Seção Temática: Balanço do Fundeb Volume 10 - $2020 \mid$ n. 23

\title{
As Múltiplas Realidades Educacionais dos Municípios no Contexto do Fundeb ${ }^{1}$
}

\author{
Thiago Alves \\ Universidade Federal de Goiás (UFG), Goiânia/GO - Brasil \\ José Marcelino de Rezende Pinto \\ Universidade de São Paulo (USP), São Paulo/SP - Brasil
}

\section{Resumo}

Este artigo visa descrever os perfis dos municípios com base no porte populacional e analisar a variação do gasto por aluno da educação básica no contexto do Fundo de Manutenção e Desenvolvimento da Educação Básica e de Valorização dos Profissionais da Educação (Fundeb). Para análise empírica, foi constituída uma base de dados referentes ao ano de 2017 com variáveis de diversas fontes oficiais. A unidade de análise foi o município. Entre vários achados, destaca-se que metade dos 5.522 municípios analisados têm gasto por aluno de até $\mathrm{R} \$ 534$ por mês e um quarto deles contam com apenas $\mathrm{R} \$ 266$ por mês. Além de baixo em relação aos países desenvolvidos da OCDE, o investimento por aluno é muito desigual entre os municípios. Os resultados reforçam a importância de maior aporte de recursos da União ao Fundeb e do aperfeiçoamento dos mecanismos redistributivos do fundo para gerar maior equidade nas condições de oferta de ensino das redes municipais brasileiras.

Palavras-chave: Fundeb. Gasto por aluno. Financiamento da Educação Básica. Políticas Educacionais.

\section{The Multiple Educational Realities of Cities in the Context of Fundeb}

\section{Abstract}

This article aims to describe the profiles of the cities based on population size and to analyze the variation in spending per student of basic education in the context of the Fund for Maintenance and Development of Basic Education and Valorization of Education Professionals (Fundeb). For empirical analysis, a database for the year 2017 was created with variables from different government sources. The unit of analysis was the city. Among several findings, it is noteworthy that half of the 5,522 municipalities analyzed have spent up to $R \$ 534$ per student per month and a quarter of them have only $\mathrm{R} \$ 266$ per month. In addition to being low in relation to the developed OECD countries, investment per student is very uneven among the cities. The results reinforce the importance of a greater contribution of funds from the federal government to Fundeb and the improvement of the fund's redistributive mechanisms to generate greater equity in the conditions of teaching provision of Brazilian municipal public schools.

Keywords: Fundeb. Spending per student. School Funding. Educational Policies.

1 Este artigo é parte de pesquisa que conta com apoio do CNPq (Proc. 409861/2016-2). 
As Múltiplas Realidades Educacionais dos Municípios no Contexto do Fundeb

\section{Introdução}

Os municípios são considerados entes federativos autônomos no quadro da organização político-administrativa da federação brasileira (CF, Art. 18). Eles apresentam realidades demográficas, econômicas, político-administrativa e educacionais muito diversas. Nesse sentido, este artigo visa descrever os perfis dos municípios com base no porte populacional e analisar a variação do gasto por aluno da educação básica no contexto do Fundo de Manutenção e Desenvolvimento da Educação Básica e de Valorização dos Profissionais da Educação (Fundeb). Assim, pretende-se responder as seguintes questões: quais são as características educacionais dos municípios brasileiros? Qual é o nível de variação do gasto por aluno entre os municípios? Que características explicam a variação do gasto por aluno?

Pode-se dizer que a história dos municípios brasileiros se confunde com a própria história do País, considerando que a primeira vila, São Vicente, foi fundada por Martin Afonso de Souza em 1532 (BRAGA, 2008). Como aponta Leal (1978), analisando o fenômeno do coronelismo, a relação entre o poder local e o poder central no Brasil sempre foi marcada pela ambivalência, em que os mandatários municipais garantiam a implementação das políticas centrais em troca da possibilidade de nomeação de cargos estratégicos, como o delegado, os diretores e mesmo professores das escolas públicas.

Assim, como ressalta Pinto (2014a), não há que se confundir, no Brasil, poder local com maior democracia e controle social, uma vez que a história dos municípios é marcada pela intervenção constante dos governos federal e estadual mediada pelos mandatários locais, em geral, representantes diretos ou indiretos do poder econômico.

Outra característica que permeia o município brasileiro ao longo de sua história é a falta de recursos tributários - fator que explica a sua dependência dos demais níveis de governo. A Constituição de 1988 minorou, em parte, essa fragilidade financeira, mas as políticas posteriores de municipalização da educação e da saúde acirraram ainda mais essa ausência de autonomia.

Uma medida do esforço do Estado em relação ao investimento em educação pública é o 'gasto por aluno'2. O 'gasto público educacional', conforme Castro (2011), refere-se ao montante de recursos financeiros aplicados no setor público com vistas ao atendimento das necessidades e direitos educacionais.

A análise do gasto por aluno dos municípios no âmbito do Fundeb faz-se necessária para compreender até que ponto o fundo tem contribuído para elevar e equalizar o gasto em educação pública entre as localidades no âmbito da federação, uma vez que o Brasil tem realizado um investimento médio por aluno muito mais baixo do que os países desenvolvidos e muito desigual internamente. Segundo o anuário Education at a Glance da Organisation for Economic Co-operation and Development (OECD, 2018), em 2015, o gasto público anual por

2 Outra medida do investimento em educação comumente citada é o 'Percentual do Produto Interno Bruto (Pib) investido em educação'. Todavia, a comparação desse indicador entre os países é imprópria devido à diferença do tamanho do Pib e da população em idade escolar. 
As Múltiplas Realidades Educacionais dos Municípios no Contexto do Fundeb

aluno dos países membros da OECD foi de US\$ppp 38.631 na etapa equivalente aos anos iniciais do ensino fundamental. Esse valor foi significativamente menor no Brasil (US\$ppp 3.762).

A partir dessa introdução, este artigo está estruturado em quatro seções: (i) análise da evolução das matrículas das redes estaduais e municipais e da receita do Fundeb; (ii) aspectos metodológicos; (iii) caracterização do contexto educacional por porte dos municípios; (iv) análise do gasto por aluno; e (v) considerações finais e implicações para a política de financiamento.

\section{Matrículas e recursos dos municípios no contexto do Fundeb}

A aprovação do Fundeb através da Emenda Constitucional 53/2006 (regulamentado pela Lei $n^{\circ} 11.484 / 2007$ ) trouxe grandes esperanças para estados e municípios no sentido de enfrentar-se os principais problemas decorrentes dos dez anos de experiência com o Fundo de Manutenção e Desenvolvimento do Ensino Fundamental e de Valorização do Magistério (Fundef, Lei $n^{\circ}$ 9.424/1996). A política de fundos, inicialmente o Fundef (1997-2006) e, agora, o Fundeb, ao redistribuir recursos no âmbito de cada estado da federação, considerando as matrículas (Ensino Fundamental, no caso do Fundef, e educação básica, no caso do Fundeb), alterou a divisão de responsabilidade pela oferta da educação básica entre estados e municípios. É o que mostra o Gráfico 1 para o período 1998-2017, considerando as etapas de prioridade exclusiva respectivas de estados e municípios (educação infantil e ensino médio) e as matrículas totais na educação básica de cada ente federado.

\section{Gráfico 1 - Número de matrículas das redes estaduais e municipais, Brasil, 1998-2017}

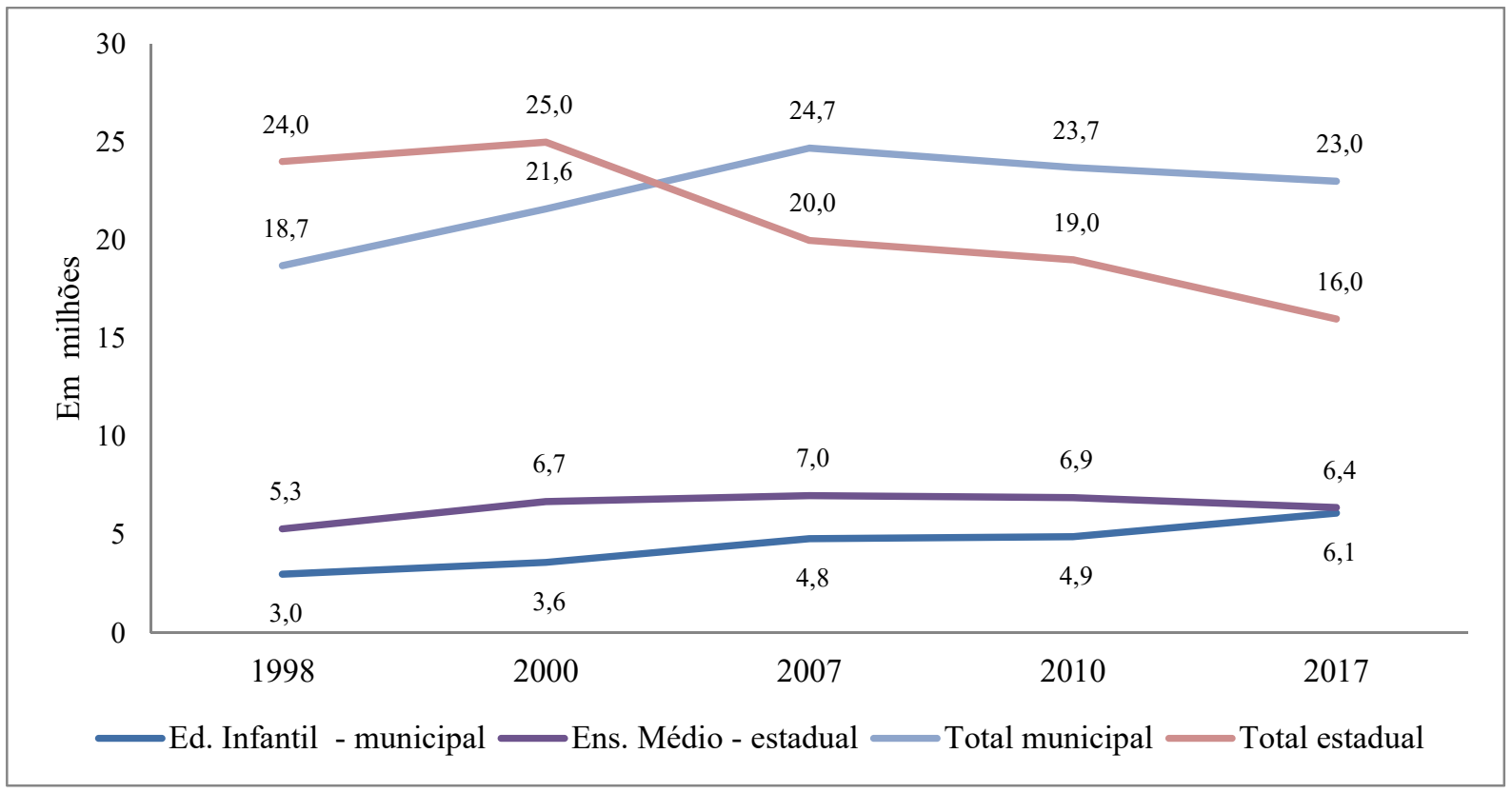

Fonte: Elaborado pelos autores a partir dos dados do Censo Escolar (INEP).

3 O purchasing power parity (PPP) é um método alternativo à taxa de câmbio e útil para comparações internacionais. Permite analisar quanto uma determinada moeda poderia comprar se não fosse influenciada por fatores que determinam a taxa de câmbio. 
As Múltiplas Realidades Educacionais dos Municípios no Contexto do Fundeb

O Gráfico 1 mostra o processo de municipalização da oferta da educação básica pública no Brasil. Isso decorreu de uma redução das matrículas estaduais associada a uma expansão da rede municipal. Assim, as matrículas estaduais caíram 33\% no período de 1998 a 2017, com redução de quatro milhões no período do Fundef e quatro milhões sob o Fundeb até 2017. No mesmo período, a matrícula municipal na educação básica cresceu $23 \%$, atingindo um pico em $2007(+32 \%)$ e começou a reduzir a partir de então. Quanto à participação no total, a rede municipal saiu de 44\%, em 1998, atingindo 55\%, em 2007 (primeiro ano do Fundeb) e 59\%, em 2017. A rede estadual apresentou uma queda sistemática em todas as etapas e modalidades, em especial a partir de 2000. Já a rede municipal viveu um processo de ampliação constante e significativa de educação infantil no período (+103\%), inclusive no período do Fundef, enquanto no ensino fundamental a expansão se deu até 2007, iniciandose então um processo de queda. Um dado importante a se comentar nesse processo de expansão da rede municipal é que os custos por aluno da educação infantil, em especial das creches, são muito superiores àqueles praticados no ensino fundamental e médio, o que implica em maior pressão financeira sobre os municípios.

Essa dificuldade de expansão e, como já visto, as mudanças ocorridas na divisão de responsabilidade pela oferta da educação básica entre estados e municípios relacionam-se diretamente com o modelo de financiamento da educação. Atualmente, o financiamento das escolas estaduais e municipais de educação básica tem as seguintes fontes principais:

- Vinculação constitucional da receita líquida de impostos (RLI) de estados e municípios para custear despesas classificadas como manutenção e desenvolvimento de ensino (MDE);

- Contribuição social do salário-educação como fonte adicional (Art. 212, § 5, CF/88);

- Recursos adicionais do governo federal ${ }^{4}$, principalmente sob a forma de complementação da União ao Fundeb ${ }^{5}$.

Para exemplificar o impacto financeiro de cada uma das fontes, segundo dados do Siope/FNDE, em termos nacionais, em 2018, esse sistema de financiamento propiciou uma receita anual estimada em $\mathrm{R} \$ 260,8$ bilhões, sendo:

- $\mathrm{R} \$ 225$ bilhões (86,3\% do total) oriundos da RLI de estados e municípios;

- $\mathrm{R} \$ 21,9$ bilhões (8,4\% do total) da contribuição social do salário-educação; e

- $\mathrm{R} \$ 13,8$ bilhões (5,3\% do total) da complementação da União ao Fundeb.

O Fundeb, cujo caráter é essencialmente redistributivo, movimentou, em 2018, cerca de $R \$ 152,6$ bilhões (58,5\% do total da receita), sendo $R \$ 138,8$ bilhões das receitas vinculadas

4 Os recursos da União são oriundos da vinculação constitucional de, no mínimo, 18\% da RLI do governo federal para MDE e de recursos adicionais oriundos de outras fontes que são repassados a estados e municípios para a educação básica, em geral, como transferências voluntárias da União. Essa forma de transferência tem sofrido forte queda nos últimos 5 anos.

5 A complementação da União observa os seguintes dispositivos da Lei $n^{\circ}$ 11.494/2007: "Art. 4 ㅇA União complementará os recursos dos Fundos sempre que, no âmbito de cada Estado e no Distrito Federal, o valor

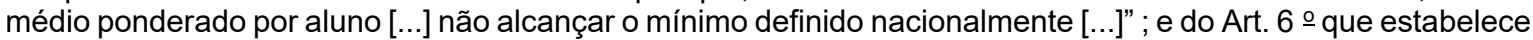
que a complementação da União será de, no mínimo, $10 \%$ do total dos recursos aportados ao Fundeb por estados e municípios, sendo que (art. $5^{\circ}$ ) a vinculação de recursos para manutenção e desenvolvimento do ensino estabelecida no art 212 da CF suportará, no máximo, 30\% (trinta por cento) da complementação da União. 
As Múltiplas Realidades Educacionais dos Municípios no Contexto do Fundeb

de estados e municípios e $\mathrm{R} \$ 13,8$ bilhões de complementação da União. Esses números ressaltam a importância desse fundo, que tem $91 \%$ de sua receita originada dos recursos dos entes federativos subnacionais. Embora o Fundeb seja a principal fonte de financiamento da educação básica para grande parte dos municípios, ele não representa a totalidade dos recursos (para a metade dos municípios, os recursos do fundo, como se verá, representam pelo menos $71 \%$ das receitas da educação básica). Os recursos adicionais ao fundo são originários da vinculação à educação da RLI arrecadada diretamente pelos municípios e de parte das transferências de impostos recebidas que não se destinam ao Fundeb (5\% da mesma cesta de tributos do Fundeb). Essas fontes adicionais não estão submetidas às regras redistributivas do fundo e, portanto, tendem a gerar perfis extremante variados na capacidade de gasto por aluno em favor dos municípios com maior capacidade de arrecadação (ALVES; SILVEIRA; SCHNEIDER, 2019), como será discutido em seção posterior. O Gráfico 2 apresenta a evolução da receita do Fundeb.

Gráfico 2 - Evolução da receita consolidada do Fundeb, Brasil, 2010-2019 (em R\$ bilhões)

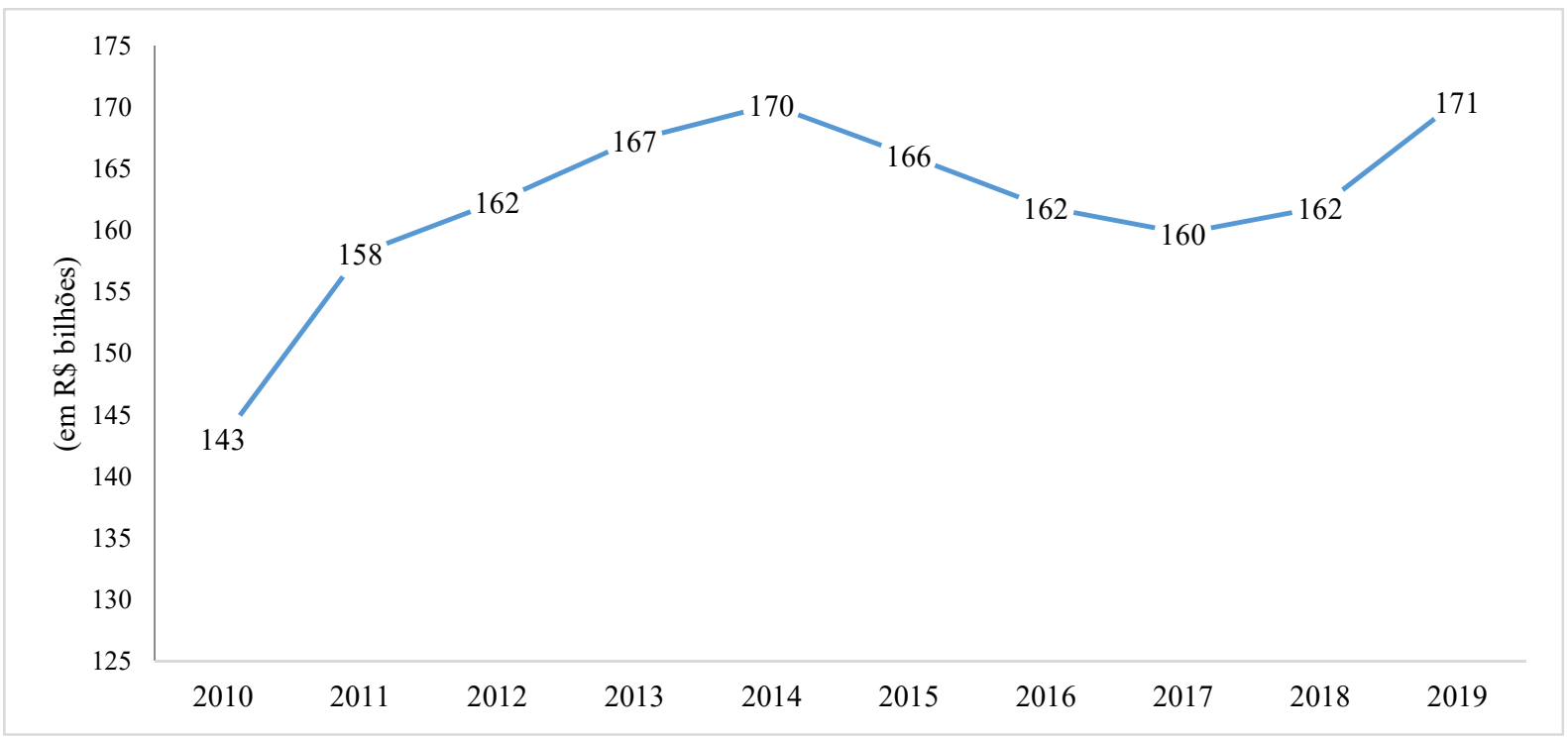

Nota: $\left({ }^{*}\right)$ Valores corrigidos pelo IPCA/IBGE para dezembro 2019.

Fonte: Elaborado pelos autores a partir dos dados da plataforma 'Transferências Constitucionais' / Secretaria do Tesouro Nacional.

Como as principais fontes de recursos do Fundeb são o ICMS, FPM e FPE, a receita do fundo está diretamente ligada à atividade econômica. Como mostra o Gráfico 2, de 2014 a 2017 , período de forte recessão econômica, o fundo teve uma queda superior a $\mathrm{R} \$ 10$ bilhões em seus recursos, o que pode ajudar a entender a queda nas matrículas da educação básica identificada no Gráfico 1. Não obstante a ligeira recuperação em 2018 e 2019, com a pandemia do Covid-19 e seus inexoráveis impactos na atividade econômica, a queda de receita do fundo deve se acentuar (FINEDUCA, 2020).

Outra informação relevante quanto ao caráter redistributivo do Fundeb entre as redes estaduais e municipais no âmbito de cada unidade federativa, segundo a lógica que o preside, na qual o dinheiro segue a matrícula, é indicada no Gráfico 3 , um progressivo processo de ampliação da parcela dos recursos do fundo que é destinada aos municípios. Observa-se que esse crescimento tem relação próxima ao processo de municipalização analisado no Gráfico 1. 
Gráfico 3 - Evolução da participação municipal nos recursos distribuídos pelo Fundeb, Brasil, 2007-2019 (em valores relativos \%)

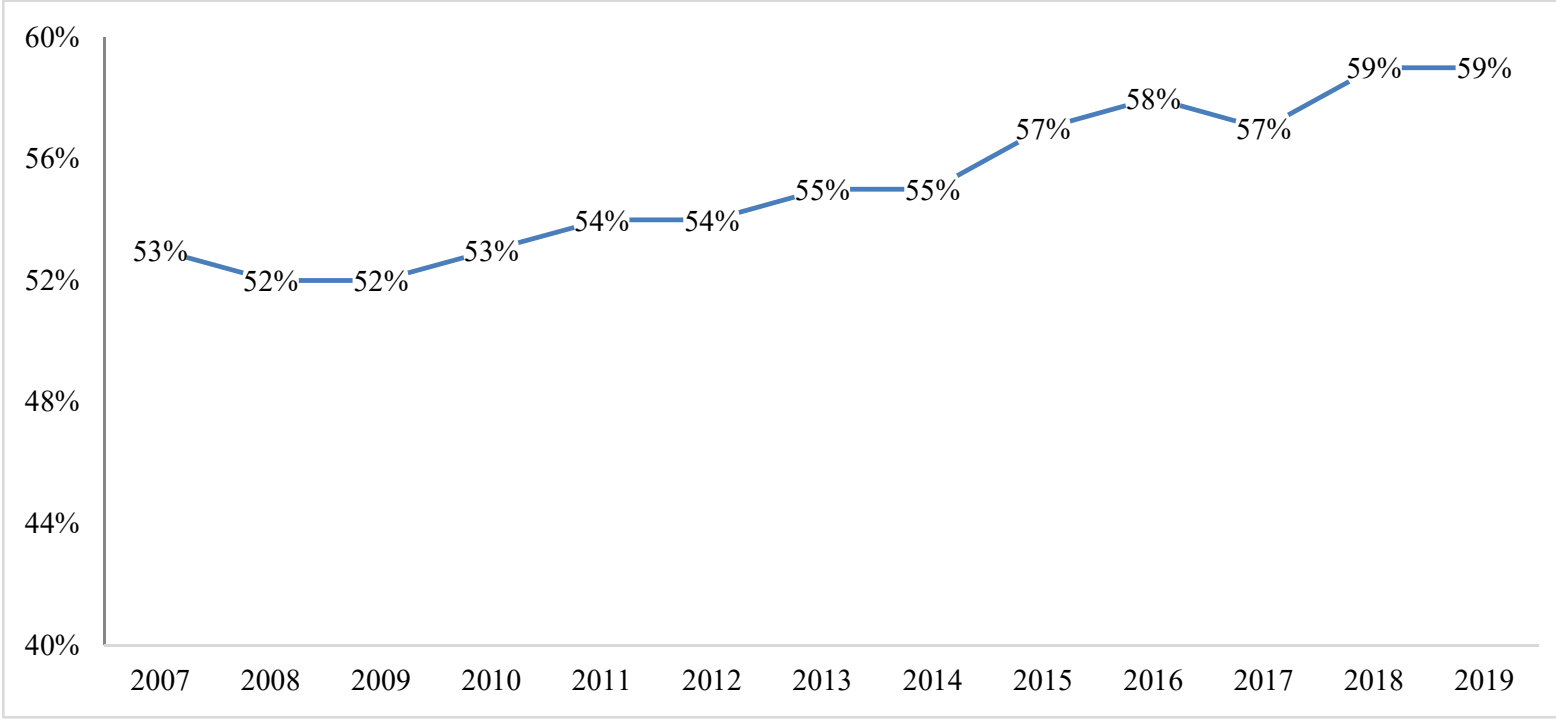

Fonte: Elaborado pelos autores a partir dos dados da plataforma 'Transferências Constitucionais', Secretaria do Tesouro Nacional.

\section{Aspectos Metodológicos}

A análise empírica se iniciou com a constituição de uma base de dados referentes ao ano de 2017 com variáveis de diversas fontes. A unidade de análise foi o município. Observando os limites de cada fonte, foram levantados dados para os 5.570 municípios brasileiros. O Quadro 1 apresenta as variáveis e suas respectivas fontes.

Neste artigo, a análise do financiamento da educação está baseada nos dados de receitas e despesas dos municípios. A obrigatoriedade de prestação dessas informações em instrumentos de transparência da gestão fiscal, como o 'relatório resumido da execução orçamentária' (RREO), é estabelecida pela Constituição (Art. $165 \S 3^{\circ}$ ) e pela Lei de Responsabilidade Fiscal (Lei Complementar $n^{\circ} 101 / 2000$ - Art. 48) mas, cabe ressaltar, são informações de caráter declaratório. Desse modo, a fidedignidade da análise das despesas depende da precisão das informações prestadas. Nesse sentido, a inclusão de itens de despesa como o pagamento de aposentadoria do pessoal da educação, por exemplo, pode levar à superestimação dos gastos. 
Quadro 1 - Variáveis utilizadas e fontes de dados

\begin{tabular}{|c|c|c|}
\hline Aspecto & Variável & Fonte \\
\hline $\begin{array}{l}\text { Estrutura educacional } \\
\text { local }\end{array}$ & $\begin{array}{l}\text { Existência de secretaria exclusiva de educação } \\
\text { Formação do/a secretário/a de educação } \\
\text { Sexo do/a secretário/a de educação } \\
\text { Cor/etnia do/a secretário/a de educação } \\
\text { Forma de escolha dos diretores de escolas } \\
\text { Características do Conselho Municipal de Educação }\end{array}$ & $\begin{array}{l}\text { Perfil dos municípios Brasileiros/IBGE - } \\
2018\end{array}$ \\
\hline \multirow[b]{3}{*}{ Contexto da oferta } & \multirow{3}{*}{$\begin{array}{l}\text { População } \\
\text { Porte populacional }{ }^{1} \\
\text { Taxa de atendimento }{ }^{2} \\
\text { Número de matrículas (municipal + conveniada) } \\
\text { Número de escolas municipais } \\
\text { Proporção de matrículas urbanas } \\
\text { Razão matrículas rede municipal/matrículas total }\end{array}$} & Estimativa populacional do IBGE, 2017 \\
\hline & & Censo demográfico/IBGE, 2000 e 2010 \\
\hline & & Censo Escolar/Inep, 2017 \\
\hline Receitas & $\begin{array}{l}\text { Receita Líquida de impostos e transferências por habitante }{ }^{3} \\
\text { Receita por aluno (por mês) }\end{array}$ & \multirow{3}{*}{$\begin{array}{l}\text { Dados analíticos Siope/Fnde e } \\
\text { Finbra/STN, } 2017\end{array}$} \\
\hline Recursos do Fundeb & $\begin{array}{l}\text { \% Participação do Fundeb na receita para educação }{ }^{5} \\
\% \text { Receita adicional ao Fundeb (RaF) } \\
{ }^{6} \\
\text { Resultado Líquido Fundeb - receitas: recebidas/destinadas }{ }^{7}\end{array}$ & \\
\hline $\begin{array}{l}\text { Perfil do gasto em } \\
\text { educação básica }\end{array}$ & $\begin{array}{l}\text { Gasto por aluno (por mês) } \\
{ }^{8} \\
\text { Gasto por aluno Fundeb (por mês) } \\
\text { Razão gasto-Fundeb/gasto total }\end{array}$ & \\
\hline
\end{tabular}

Notas:

1 - Portes populacionais definidos pelo IBGE: 1 = até 5.000 habitantes; 2 = 5.001-10.000; $3=10.001-20.000 ; 4=20.001$ $50.000 ; 5=50.001-100.000 ; 6=100.001-500.000 ; 7=$ mais de 500.000 habitantes;

$2-\mathrm{TA}=$ [Número de pessoas na faixa etária i que frequenta escola ou creche / população na faixa etária idade i];

3 - A RLI é a "receita resultante de impostos, compreendida a proveniente de transferências". Base de cálculo da vinculação constitucional de recursos para a educação (Art. 212 da CF);

4 - Inicialmente é calculada a 'Receita Potencial mínima vinculada para a educação básica' (RPEb), que é calculada pela seguinte fórmula: [RLI x 25\% - receitas destinadas ao Fundeb + receitas recebidas do Fundeb + Salário Educação (cota municipal) + complementação da União ao Fundeb]. Em seguida, calcula-se a 'Receita por Aluno' = [RPEb / número de matrículas (rede municipal + instituições conveniadas com a prefeitura) / 12]. São apresentados valores mensais para facilitar a compreensão dos valores no contexto brasileiro;

5 - \% Participação do Fundeb na receita = [(Receita recebida do Fundeb + complementação da União) / RPEb)];

6 - \% Receita adicional ao Fundeb (RaF): ([25\% das receitas de impostos NÃO destinadas ao Fundeb $+5 \%$ das receitas de impostos destinadas ao Fundeb + Salário Educação] / 'Receita Potencial mínima vinculada para a educação básica' (RPEb)); 7 - RL Fundeb: [receitas recebidas do Fundeb / receitas destinadas ao Fundeb]. Valores maiores do que UM indicam que o município recebe mais recursos do que destina;

8 - Gasto por aluno: [Despesa em educação básica / número de matrículas (rede municipal + instituições conveniadas com a prefeitura) / 12]. São apresentados valores mensais para facilitar a compreensão no contexto brasileiro;

9 - Gasto por aluno Fundeb: [Despesa em educação básica com recursos do Fundeb / número de matrículas (rede municipal + instituições conveniadas com a prefeitura) / 12]. São apresentados valores mensais para facilitar a compreensão no contexto brasileiro;

10 - Razão gasto-Fundeb/gasto total = [Gasto por aluno Fundeb / Gasto por aluno].

Fonte: Elaborado pelos autores.

\section{Características dos municípios brasileiros}

O Gráfico 4 apresenta a grande evolução do número de municípios brasileiros em 145 anos. Desde 1872, o número de municípios cresceu quase nove vezes, com maiores taxas de crescimento nos períodos pós constituições de 1946 e 1988. 
As Múltiplas Realidades Educacionais dos Municípios no Contexto do Fundeb

Gráfico 4 - Evolução do número de municípios brasileiros, Brasil, 1872-2017

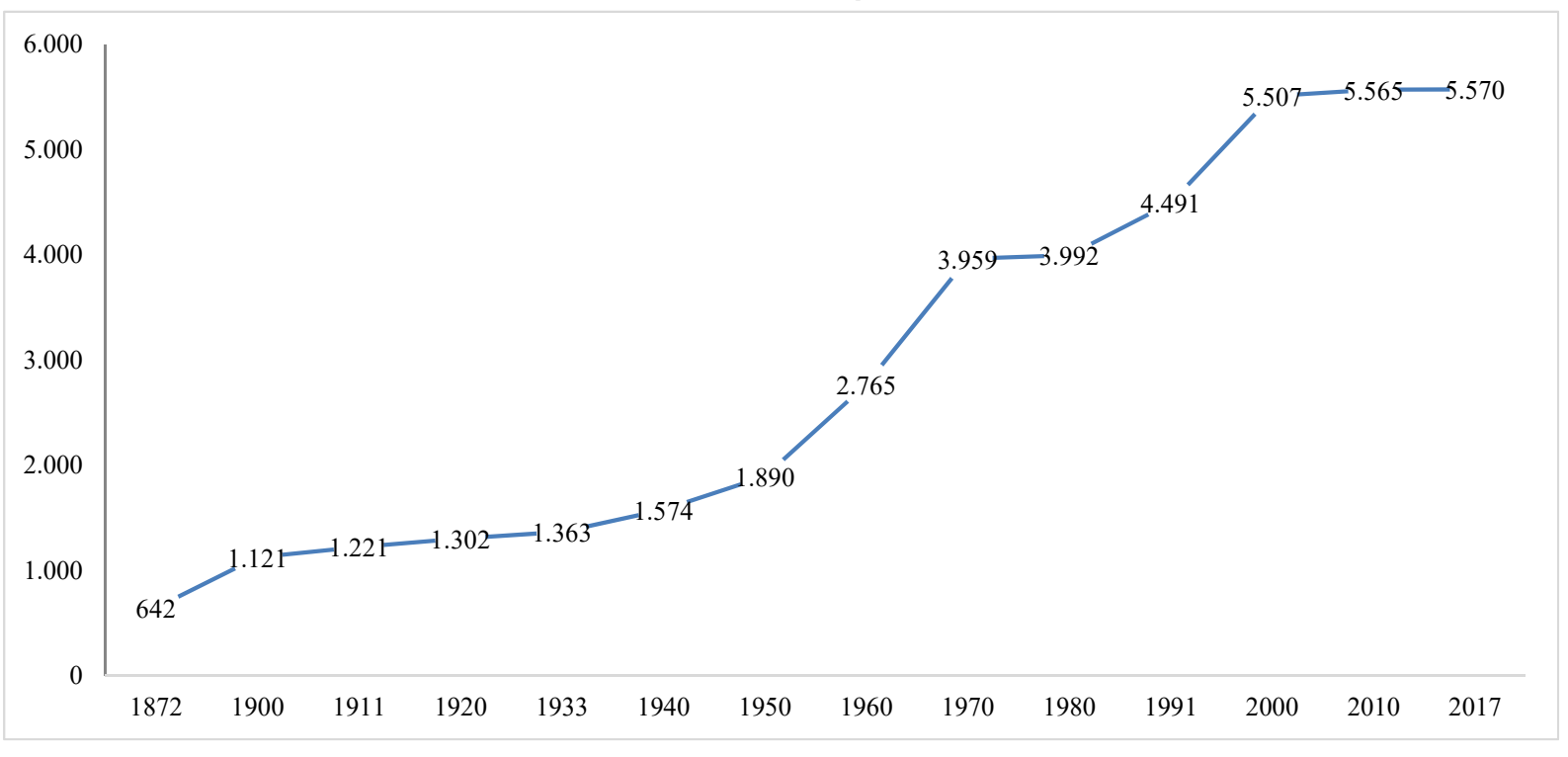

Fonte: IBGE (2010), de 1872 a 2010 e PNAD/IBGE (2017).

É comum se ouvir que o Brasil possui um número exagerado e artificial de municípios. O governo Bolsonaro chegou a propor a extinção de 1.253 municípios com menos de 5 mil habitantes por não terem condições de se manter sem ajuda do governo federal (GOVERNO..., 2019). Contudo, essa questão é complexa quando se estabelece comparação com alguns países do mundo. A título de exemplo, os EUA (330 milhões de habitantes e área total de 9,5 milhões de $\mathrm{km}^{2}$ ) possuía, em 2017, cerca de 19,5 mil cidades (cities), a França (67 milhões de habitantes, 0,6 milhões de $\mathrm{km}^{2}$ ), 37 mil comunas e, a Itália (60 milhões de habitantes, 0,3 milhões de $\mathrm{km}^{2}$ ), quase 8 mil comunas. Como se constata, essa questão relaciona-se com a história e dimensão dos países.

A Tabela 1 apresenta algumas características dos municípios brasileiros, considerando os portes populacionais. A questão do porte dos municípios tem sido pouco explorada nos estudos educacionais e seu efeito foi potencializado com o intenso processo de municipalização da oferta já comentado e decorrente direto da política de fundos. Pelos dados da Tabela 1 , constata-se que mais de dois terços dos municípios brasileiros $(68,3 \%)$ possuem menos de 20 mil habitantes e, $88,1 \%$, menos de cinquenta mil. Somente $5,6 \%$ possuem mais de 100 mil habitantes. Como as universidades e instituições de pesquisa tendem a se localizar nas maiores cidades, muitas vezes nas capitais, muitos dos aspectos envolvendo o financiamento da educação são analisados a partir da ótica desses municípios, que possuem uma estrutura financeira e administrativa que foge ao padrão de nove décimos dos municípios brasileiros. 
As Múltiplas Realidades Educacionais dos Municípios no Contexto do Fundeb

Tabela 1 - Perfil dos municípios, por porte populacional, Brasil, 2018

\begin{tabular}{|c|c|c|c|c|c|c|c|c|}
\hline \multirow{2}{*}{ Aspectos } & \multirow{3}{*}{ Total } & \multicolumn{6}{|c|}{ Porte populacional (em milhares de habitantes) } \\
\cline { 3 - 9 } & & até 5 & $5-10$ & $10-20$ & $20-50$ & $50-100$ & $100-500$ & $>500$ \\
\hline
\end{tabular}

Número de municípios (2017)

\begin{tabular}{|l|r|rrrrrrr|}
\hline $\mathrm{N}$ & 5.570 & 1.235 & 1.215 & 1.352 & 1.103 & 355 & 268 & 42 \\
$\%$ & $100 \%$ & $22 \%$ & $22 \%$ & $24 \%$ & $20 \%$ & $6 \%$ & $5 \%$ & $1 \%$ \\
\hline
\end{tabular}

Participação da rede municipal na matrícula pública do ensino fundamental ${ }^{1}$

\begin{tabular}{|l|lllllll|}
\hline 1998 & $48 \%$ & $52 \%$ & $57 \%$ & $56 \%$ & $50 \%$ & $40 \%$ & $37 \%$ \\
2007 & $59 \%$ & $63 \%$ & $69 \%$ & $70 \%$ & $68 \%$ & $57 \%$ & $49 \%$ \\
2017 & $67 \%$ & $69 \%$ & $76 \%$ & $77 \%$ & $75 \%$ & $66 \%$ & $56 \%$ \\
\hline
\end{tabular}

Existência de uma secretaria exclusiva de educação

\begin{tabular}{|l|r|rrrrrrr|}
\hline Secretaria exclusiva & $57 \%$ & $42 \%$ & $49 \%$ & $58 \%$ & $64 \%$ & $77 \%$ & $86 \%$ & $89 \%$ \\
\hline
\end{tabular}

Caracterís ticas da secre tária/o de educação

\begin{tabular}{|c|c|c|c|c|c|c|c|c|}
\hline Formação em nível superior ou mais & $96 \%$ & $93 \%$ & $95 \%$ & $96 \%$ & $97 \%$ & $97 \%$ & $99 \%$ & $98 \%$ \\
\hline Sexo Feminino & $70 \%$ & $76 \%$ & $71 \%$ & $70 \%$ & $67 \%$ & $63 \%$ & $62 \%$ & $59 \%$ \\
\hline Cor: Preta ou Parda & $39 \%$ & $32 \%$ & $42 \%$ & $45 \%$ & $44 \%$ & $34 \%$ & $28 \%$ & $20 \%$ \\
\hline
\end{tabular}

Caracterís ticas do Conselho Municipal de Educação (CME)

\begin{tabular}{|c|c|c|c|c|c|c|c|c|}
\hline CME com + soc. civil & $17 \%$ & $14 \%$ & $15 \%$ & $18 \%$ & $19 \%$ & $20 \%$ & $21 \%$ & $37 \%$ \\
\hline CME deliberativo & $84 \%$ & $83 \%$ & $83 \%$ & $83 \%$ & $83 \%$ & $88 \%$ & $89 \%$ & $98 \%$ \\
\hline Capacitação de conselheiros & $7 \%$ & $6 \%$ & $4 \%$ & $6 \%$ & $8 \%$ & $15 \%$ & $13 \%$ & $15 \%$ \\
\hline CME com dotação orçamentária & $8 \%$ & $5 \%$ & $5 \%$ & $6 \%$ & $9 \%$ & $15 \%$ & $18 \%$ & $33 \%$ \\
\hline $\mathrm{CME} \mathrm{c} /$ representante sindical docente & $44 \%$ & $26 \%$ & $35 \%$ & $47 \%$ & $57 \%$ & $62 \%$ & $68 \%$ & $78 \%$ \\
\hline
\end{tabular}

Forma de escolha dos dire tores de escolas

\begin{tabular}{|c|c|c|c|c|c|c|c|c|}
\hline Concurso & $5 \%$ & $5 \%$ & $4 \%$ & $4 \%$ & $6 \%$ & $11 \%$ & $13 \%$ & $11 \%$ \\
\hline Eleição & $18 \%$ & $12 \%$ & $15 \%$ & $16 \%$ & $21 \%$ & $27 \%$ & $35 \%$ & $44 \%$ \\
\hline Processo seletivo & $3 \%$ & $1 \%$ & $1 \%$ & $2 \%$ & $3 \%$ & $6 \%$ & $13 \%$ & $15 \%$ \\
\hline outras & $5 \%$ & $5 \%$ & $4 \%$ & $4 \%$ & $5 \%$ & $6 \%$ & $8 \%$ & $15 \%$ \\
\hline
\end{tabular}

Nota: (1) Não foram consideradas as matrículas das escolas federais porque representam pequeno percentual da oferta (0,08\% em 2017).

Fonte: Elaborada pelos autores a partir do levantamento do perfil dos municípios brasileiros (IBGE) e Censo Escolar (Inep).

Os dados da Tabela 1 também mostram uma relação entre porte dos municípios e grau de participação da rede municipal nas matrículas do ensino fundamental - aqui denominada por 'municipalização' dessa etapa. De uma maneira geral, os municípios acima de 100 mil habitantes tendem a ser menos municipalizados, o que pode explicar sua maior capacidade de atendimento na faixa etária das creches. Em todos os portes houve um avanço significativo da municipalização, sendo mais intenso nos municípios entre 100 mil e 500 mil (crescimento de $65 \%$ na taxa), e naqueles com mais de 500 mil, e entre 50 mil e 100 mil (ambos em torno de 
As Múltiplas Realidades Educacionais dos Municípios no Contexto do Fundeb

$50 \%$ ). Nos portes mais municipalizados (entre 10 mil e 50 mil), em que o Nordeste tem um peso significativo, houve também um avanço vigoroso, atingindo-se uma taxa superior a $75 \%$. Levantamento feito por Pinto (2000b) mostra que nos 30 anos que antecedem o Fundef essa participação municipal situava-se, em média, na faixa de 30\%.

Quanto à estrutura dos órgãos educacionais dos municípios, embora possa se argumentar que um município não precisa, necessariamente, possuir uma secretaria exclusiva de educação para atender com qualidade, é evidente que, dado o avanço da municipalização e a complexidade do setor, preocupa saber que cerca de $43 \%$ dos municípios não atendem esse requisito. Os dados mostram que, quanto menor o município, mais municipalizado e menos se encontra uma secretaria exclusiva.

Um dado positivo evidenciado na Tabela 1 é que quase a totalidade dos secretários apresentam formação em nível superior, com pequena variação, considerando o porte do município, embora uma diferença de $5 \%$ entre os de maior e menor porte. Contudo, no total, menos da metade possui formação em Pedagogia e, nos maiores, apenas $40 \%$. Esse fato é preocupante, porque para ser diretor de escola essa é a formação exigida legalmente. Quanto ao sexo, como o esperado, predomina o feminino, com $70 \%$ do total, diminuindo essa participação com o aumento do porte do município, com uma distância de $17 \%$ entre os maiores e menores. Com relação à etnia, enquanto, na população em geral, pretos e pardos representam mais de $55 \%$ do total, entre os secretários essa participação é de apenas 39\%; chegando a apenas $20 \%$ entre os municípios com mais de 500 mil habitantes, o que surpreende, pois seria de esperar uma postura menos preconceituosa em cidades maiores e mais urbanizadas. Aparentemente, não há uma relação simples entre porte e etnia dos secretários.

A existência do Conselho Municipal de Educação (CME) é exigência legal para que os municípios se organizem como sistemas. Porém, mais do que isso, é elemento central quando se pensa em uma gestão democrática do setor educacional, princípio constitucional e essencial para garantir eficiência e transparência às políticas públicas. Inicialmente, cabe comentar que, em média, $93 \%$ dos municípios possuem CME e $88 \%$ se organiza de forma paritária ou com hegemonia da representação da sociedade civil, condição essencial para um conselho de políticas públicas que de fato represente a sociedade local. Está certo que apenas $44 \%$ ( $26 \%$ no caso dos municípios de menor porte) garantem assento para representantes do sindicato dos profissionais da educação ou órgão equivalente, o que mostra uma visão restrita sobre a importância da participação organizada de uma categoria que é central para a qualidade do ensino (PINTO, 2014b). Também não é todo positivo o fato de o caráter deliberativo prevalecer em $84 \%$ dos municípios, atingindo-se $98 \%$ apenas naqueles acima de 500 mil habitantes. Cabe ressaltar que, se o poder de um conselho deliberativo já é, muitas vezes, limitado pelo Executivo, aquele que não tem esse atributo de pouco adianta existir. Merecem destaque ainda três indicadores: o fato de apenas $8 \%$ dos conselhos possuírem dotação orçamentária, condição básica para sua independência do Executivo; 7\% realizarem capacitação e $38 \%$ possuírem sala própria, o mínimo de estrutura que se espera. Considerando as diferenças para esses três indicadores, contata-se, como o esperado, que os grandes municípios apresentam taxa maiores, mas mesmo assim insuficientes, com exceção da existência de uma sala própria que atinge $100 \%$ nos municípios com mais de 500 mil habitantes (mas apenas nesses). 
As Múltiplas Realidades Educacionais dos Municípios no Contexto do Fundeb

O diretor, como se sabe, junto com os professores, é peça chave no bom funcionamento de uma escola. Como eles são escolhidos nos municípios brasileiros? A Tabela 1 mostra os dados da rede municipal e indica que, em $75 \%$ dos municípios, os diretores são escolhidos pelo chefe do Executivo - a forma mais autoritária e clientelista possível. Há uma relação inversa entre o tamanho dos municípios e a opção pela livre nomeação, o que mostra a persistência da herança coronelista que marca o município brasileiro (LEAL, 1978). Já a eleição pela comunidade escolar, que embora não seja a forma perfeita, é a única que permite uma participação mais ativa da comunidade escolar, bem como a substituição periódica do diretor da escola, em média, é praticada por $18 \%$ dos municípios, oscilando de $12 \%$, entre o grupo dos menores, até $44 \%$ nos municípios com mais de 500 mil habitantes. Por fim, o concurso, mecanismo pelo qual, como aponta Paro (2003), o diretor escolhe a escola, mas a escola não escolhe o diretor, que é vitalício no cargo, é a forma adotada em apenas $5 \%$ dos municípios, atingindo patamares acima de $10 \%$ apenas nos municípios com mais de 50 mil habitantes. Apresentado o perfil dos municípios brasileiros, mostrando sua diversidade em termos de porte populacional, atendimento educacional e estrutura do setor educacional, pode-se analisar de forma mais contextualizada o gasto educacional.

\section{Análise do gasto por aluno nos municípios}

A Tabela 2 apresenta medidas descritivas de 13 características dos municípios em quatro dimensões: contexto de oferta, composição das receitas para educação básica, recursos do Fundeb e perfil do gasto em educação.

Os dados revelam a grande diversidade e as múltiplas realidades dos municípios brasileiros em diferentes aspectos. O tamanho populacional é a variável que apresenta maior dispersão (CV $=587 \%$ ). Apesar da grande amplitude entre Serra da Saudade/MG, com 812 habitantes, e São Paulo/SP, com 12,1 milhões de habitantes, a Tabela 1 mostra que $90 \%$ dos municípios têm população entre 2.551 e 110.086 habitantes. O tamanho populacional tem forte consequência para o porte das redes municipais de ensino (medido pelo número de matrículas e escolas) - variáveis igualmente heterogêneas, o que gera também problemas de economia de escala. A Tabela 2 mostra que $50 \%$ dos municípios possuem até 1.639 matrículas (90\% dos municípios têm de 265 a 14.190 matrículas). Igualmente, a mediana do número de escolas é igual a 10 (sendo que $5 \%$ das menores redes têm até duas escolas e $5 \%$ das maiores têm a partir de 67 escolas). Ainda quanto ao contexto de oferta, $50 \%$ das escolas respondem por até $82,7 \%$ das matrículas urbanas. Seguindo a mesma lógica de análise, os dados da Tabela 2 também revelam que $50 \%$ dos municípios são responsáveis por pelo menos $55,8 \%$ das matrículas locais (processo de municipalização que, como se viu, se iniciou com o Fundef para o ensino fundamental, e foi mantido pelo Fundeb, que passou a redistribuir recursos no âmbito de cada estado considerando todas as matrículas da educação básica da etapa de atuação prioritária dos estados ou municípios). 
As Múltiplas Realidades Educacionais dos Municípios no Contexto do Fundeb

Tabela 2 - Análise exploratória de algumas características dos municípios', Brasil, 2017

\begin{tabular}{|c|c|c|c|c|c|c|c|}
\hline \multirow{2}{*}{ Caracte rísticas } & \multirow{2}{*}{ Unid. } & \multirow{2}{*}{ Mediana $^{2}$} & \multirow{2}{*}{$\mathbf{C V}^{3}$} & \multicolumn{4}{|c|}{ Medidas de posição ${ }^{4}$} \\
\hline & & & & $5 \%$ menor & $25 \%$ menor & $25 \%$ maior & $5 \%$ maior \\
\hline \multicolumn{8}{|l|}{ Contexto da ofe rta } \\
\hline População & $\mathrm{N}$ & 11.607 & $587 \%$ & 2.551 & 5.499 & 25.138 & 110.086 \\
\hline Número de matrículas (municipal + conveniada) & $\mathrm{N}$ & 1.639 & $434 \%$ & 265 & 688 & 3.887 & 14.190 \\
\hline Número de escolas municipais & $\mathrm{N}$ & 10 & $201 \%$ & 2 & 5 & 23 & 67 \\
\hline Proporção de matrículas urbanas & $\%$ & $82,7 \%$ & $30 \%$ & $33,4 \%$ & $60,9 \%$ & $98,3 \%$ & $100,0 \%$ \\
\hline Razão matrículas rede municipa $1 /$ matrículas total & $\%$ & $55,8 \%$ & $29 \%$ & $31,1 \%$ & $45,7 \%$ & $72,2 \%$ & $84,7 \%$ \\
\hline \multicolumn{8}{|l|}{ Receitas } \\
\hline Receita Líquida de impostos e transf. por hab. (por ano) & $\mathrm{R} \$$ & 1.758 & $63 \%$ & 840 & 1.240 & 2.606 & 4.963 \\
\hline Receita por aluno (por mês) & $\mathrm{R} \$$ & 427 & $30 \%$ & 284 & 329 & 497 & 651 \\
\hline \multicolumn{8}{|l|}{ Recursos do Fundeb } \\
\hline \% Participação do Fundeb na receita para educação & $\%$ & $71,2 \%$ & $18 \%$ & $51,2 \%$ & $63,5 \%$ & $84,2 \%$ & $90,9 \%$ \\
\hline \% Receita Própria para educação (exceto Fundeb) & $\%$ & $28,8 \%$ & $47 \%$ & $9,1 \%$ & $15,8 \%$ & $36,5 \%$ & $48,8 \%$ \\
\hline Resultado Líquido Fundeb - receitas: recebidas/destinadas & razão & 1,40 & $63 \%$ & 0,45 & 0,90 & 2,17 & 3,57 \\
\hline \multicolumn{8}{|l|}{ Perfil do gas to em educação básica } \\
\hline Gasto por aluno (por mês) & $\mathrm{R} \$$ & 534 & $41 \%$ & 326 & 411 & 675 & 979 \\
\hline Gasto por aluno c/ recursos Fundeb (por mês) & $\mathrm{R} \$$ & 292 & $16 \%$ & 235 & 266 & 326 & 380 \\
\hline Razão gasto-Fundeb/gasto total & $\%$ & $55,6 \%$ & $26 \%$ & $33,2 \%$ & $45,8 \%$ & $68,2 \%$ & $81,6 \%$ \\
\hline
\end{tabular}

Notas:

(1) Foram analisados 5.522 municípios em cada variável - exceto nas variáveis 'Receita Líquida de impostos e transferências por habitante' (5.495) e 'Resultado Líquido Fundeb - receitas: recebidas/destinadas' (5.492);

(2) Medida de posição que indica o valor central de uma distribuição de dados em ordem crescente. Indica que $50 \%$ dos valores da distribuição estão acima ou abaixo da mediana;

(3) CV: Coeficiente de Variação = [média / desvio-padrão]. É uma medida de variabilidade, dispersão ou desigualdade. Se todos os valores de uma distribuição forem iguais, o CV é igual à zero. CV $<=15 \%$ é considerado baixo (pequena variação);

(4) São percentis de uma distribuição de dados em ordem crescente. $5 \%$ menor $=5^{\circ}$ percentil; $25 \%$ menor $=1^{\circ}$ quartil; $25 \%$ maior $=3^{\circ}$ quartil e $5 \%$ maior $=95^{\circ}$ percentil.

Fonte: Elaborada pelos autores a partir de dados do Censo Escolar (Inep) 2017 e dados analíticos do Siope (FNDE) 2017.

Quanto às receitas dos municípios, a Tabela 2 evidencia que a receita líquida de impostos (RLI) por habitante é de pelo menos $\mathrm{R} \$ 1.750$ por ano, em $50 \%$ dos municípios. Tal variável expressa a capacidade de arrecadação do município (razão entre a receita própria de impostos + transferências constitucionais de impostos estaduais e federais por habitante) e é muito dispersa entre os municípios $(C V=63 \%)$. A variável receita por aluno expressa a capacidade de investimento em educação do município decorrente dos mecanismos de financiamento ${ }^{6}$. A mediana dessa variável é $\mathrm{R} \$ 427$ por mês; em $90 \%$ dos municípios seu valor varia entre R\$ 287 e R\$ 651 por mês. Esses números revelam a desigualdade de condições dos municípios para financiar o direito à educação, ainda que o Fundeb seja um mecanismo que atua na redução dessas diferenças ao redistribuir parte dos recursos vinculados à educação da RLI pelo número de matrículas.

A Tabela 2 também mostra três variáveis que descrevem os resultados do Fundeb para os municípios. Quanto à participação das receitas do fundo nos recursos vinculados para a educação em cada localidade, a mediana evidencia que o fundo corresponde a pelo menos $71,2 \%$ das receitas para a educação em $50 \%$ dos municípios (e pelo menos $84,2 \%$ em $25 \%$ das localidades). Isso mostra a relevância dos recursos do Fundeb para a maioria dos

6 'Receita Potencial mínima vinculada para a educação básica' (RPEb): [RLI x 25\% - receitas destinadas ao Fundeb + receitas recebidas do Fundeb + Salário Educação (cota municipal) + complementação da União ao Fundeb]. 
As Múltiplas Realidades Educacionais dos Municípios no Contexto do Fundeb

municípios e explica a preocupação de prefeitos, gestores educacionais e sociedade civil quanto ao final da vigência do fundo em $31 / 12 / 2020^{7}$. A variável 'receita adicional ao Fundeb $(\mathrm{RaF})^{\prime 8}$ expressa o percentual das receitas destinadas à educação adicionais às receitas oriundas do Fundeb. Um percentual de RaF mais elevado é o diferencial da capacidade de investimento em educação dos municípios com melhor dinâmica econômica e maior capacidade tributária, como, por exemplo, as capitais. Alves, Silveira e Schneider (2019) demonstraram a diferença de capacidade de investimento em educação de três municípios de Goiás. Os resultados para a variável 'resultado líquido do Fundeb' informam que $50 \%$ dos municípios apresentam resultado positivo (recebem mais do que destinam), com um recurso adicional de pelo menos $40 \%$ em relação aos recursos destinados ao fundo. $25 \%$ dos municípios recebem até $90 \%$ do que destinam (10\% a menos do que destinam) e $25 \%$ dos municípios recebem, pelo menos, $117 \%$ a mais do que destinam. Essa balança está ligada basicamente ao tamanho da participação da rede municipal nas matrículas da educação básica e à estrutura da receita, em especial do ICMS e FPM. Os municípios muito dependentes do FPM são penalizados pelos mecanismos de transferência do Fundeb.

A Tabela 2 também expressa o resultado de variáveis descritoras do gasto em educação. A variável central dessa análise é o gasto por aluno/mês cuja mediana é igual a $\mathrm{R} \$ 534$ por mês. Todavia, a diferença entre os municípios com $5 \%$ dos menores valores (R\$ $326 /$ mês) e aqueles com $5 \%$ dos maiores valores (R\$ 979/mês) é de três vezes. Essa diferença evidencia os limites dos mecanismos de financiamento previstos no modelo atual do Fundeb em equalizar a capacidade de investimento em educação dos entes federativos subnacionais e, claramente, põe em risco o princípio da "igualdade de condições para o acesso e permanência na escola" (Art. 206, CF, inciso I) no âmbito da federação, no que depender do gasto público em educação. Quando isolada a despesa com recursos do Fundeb para formar o indicador 'gasto por aluno Fundeb', verifica-se que este representa pelo menos $55,6 \%$ em metade dos municípios. O melhor caminho para reduzir drasticamente essas diferenças é ampliar a complementação da União ao Fundeb (que ainda é muito restrita) e alterar a fórmula de repasse dessa complementação, de forma a considerar a disponibilidade total de recursos por aluno de cada ente federado, de tal forma que municípios "pobres" de estados considerados "ricos" venham a recebê-la, e vice-versa, conforme a discussão atual no Congresso Nacional sobre o novo Fundeb.

A Tabela 3 apresenta o gasto por aluno das redes municipais em cada estado. Vale ressaltar que o Fundeb se constitui de 26 fundos estaduais e um fundo distrital no DF, sem redistribuição de recursos entre estados e o DF, e que o recurso aportado pela complementação da União foi destinado a apenas nove estados em 2017 (AL, AM, BA, CE, $\mathrm{MA}, \mathrm{PA}, \mathrm{PB}, \mathrm{PE}$ e PI)$)^{9}$.

7 A Lei 11.494/2007 (Art. 48), que regulamenta o Fundeb, estabelece que "os fundos terão vigência até 31 de dezembro de 2020". Atualmente existem duas propostas em discussão, uma na Câmara dos Deputados e outra no Senado Federal. Até o fechamento deste artigo, a Proposta de Emenda Constitucional 15/2015, que torna o Fundeb permanente, havia sido aprovada em dois turnos na Câmara dos Deputados.

$8 \%$ Receita adicional ao Fundeb (RaF): ([25\% das receitas de impostos NÃO destinadas ao Fundeb + 5\% das receitas de impostos destinadas ao Fundeb + Salário Educação] / 'Receita Potencial mínima vinculada para a educação básica' (RPEb))

9 No período de 2007 a 2017, esses nove estados são praticamente os mesmos que recebem complementação da União todos os anos. De 2011 a 2015, o Rio Grande do Norte também recebeu. Em 2007, o Amazonas não foi contemplado. 
As Múltiplas Realidades Educacionais dos Municípios no Contexto do Fundeb

Tabela 3 - Gasto por aluno mensal, resultado líquido Fundeb e razão gasto Fundeb em relação ao total por estado, Brasil, 2017

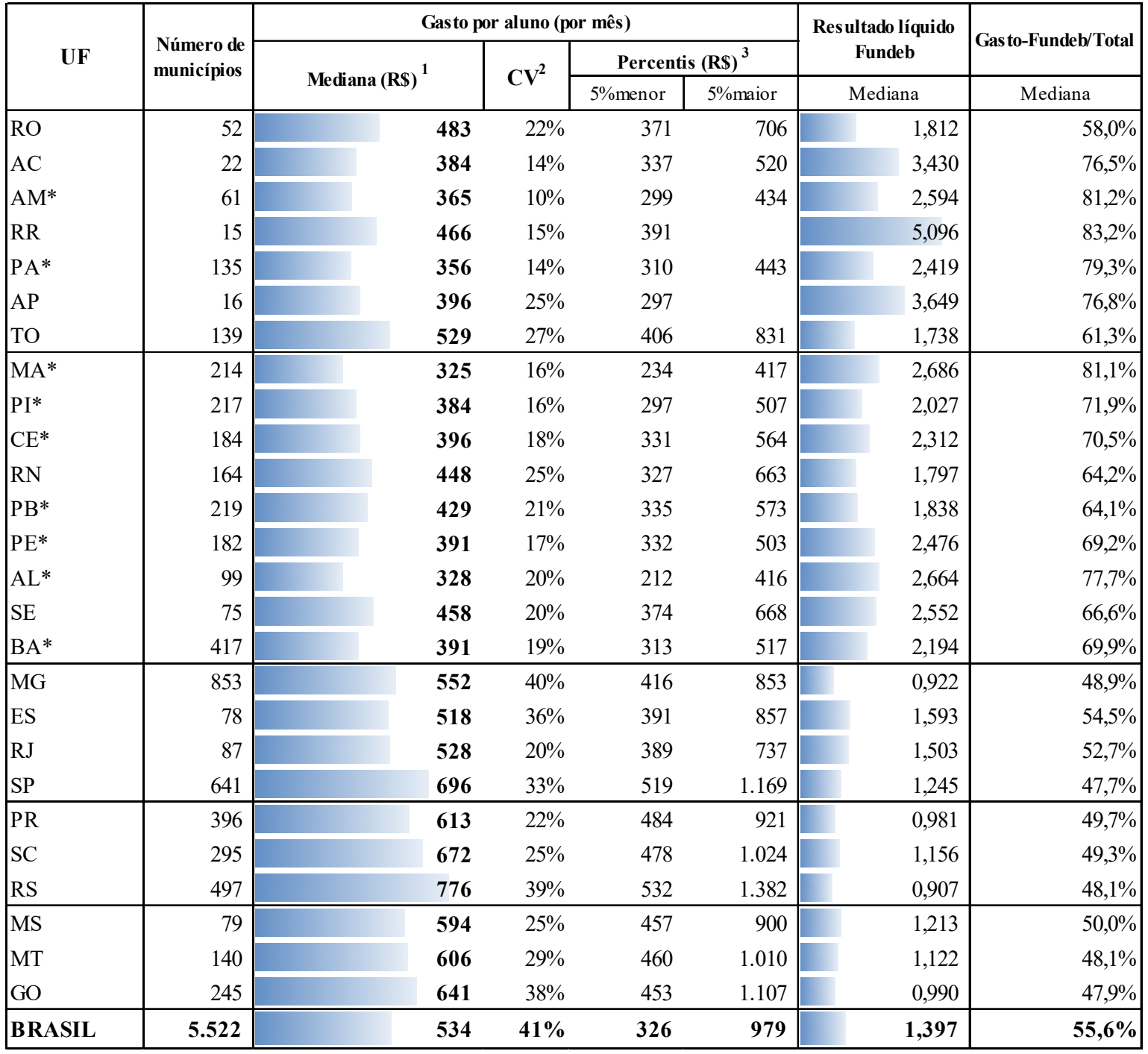

Notas:

(1) Medida de posição que indica o valor central de uma distribuição de dados em ordem crescente. Indica que $50 \%$ dos valores da distribuição estão acima ou abaixo da mediana;

(2) CV: Coeficiente de Variação = [média / desvio-padrão]. É uma medida de variabilidade, dispersão ou desigualdade. Se todos os valores de uma distribuição forem iguais, o CV é igual à zero. CV $<=15 \%$ é considerado baixo (pequena variação);

(3) São percentis de uma distribuição de dados em ordem crescente. $5 \%$ menor $=5^{\circ}$ percentil; $25 \%$ menor $=1^{\circ}$ quartil; $25 \%$ maior $=3^{\circ}$ quartil e $5 \%$ maior $=95^{\circ}$ percentil.

${ }^{*}$ ) Estados que receberam a complementação da União.

Fonte: Elaborada pelos autores a partir de dados do Censo Escolar (Inep) 2017 e dados analíticos do Siope (FNDE) 2017.

Os dados da Tabela 3 reforçam o entendimento de que, em alguma medida, o financiamento da educação básica apresenta uma conformação em cada unidade federada, devido à constituição do fundo, às diferenças da dinâmica populacional, ao perfil da oferta educacional construída historicamente e à capacidade de arrecadação dos entes. Equalizar a capacidade de investimento em educação, tarefa fundamental para a equalização das condições para a garantia do direito à educação, é um dos grandes desafios do federalismo educacional brasileiro.

Antes da análise dos dados por estado, é importante salientar que esse estudo não analisa o nível 'ideal' de gasto por aluno. Isso remeteria a discussões sobre a concepção e 
cálculo do Custo-Aluno Qualidade (CAQ), conforme estabelece as estratégias 20.6, 20.7, 20.8 e 20.10 do Plano Nacional de Educação (PNE - Lei n 13.005/2014), o Art. 74 da LDB ${ }^{10}$ e Art. 13 da Lei que regulamenta o Fundeb (Lei $n^{\circ} 11.494 / 2007$ ). Todos esses dispositivos legais não são integralmente cumpridos. Logo, o financiamento das escolas públicas brasileiras não se baseia em valores de gastos por aluno que assegurem condições para o cumprimento do princípio constitucional da "garantia de padrão de qualidade" (Art. 206 da CF, inciso VII). Isso posto, a Tabela 3 mostra que $\mathrm{R} \$ 534$ por mês foi a mediana do gasto por aluno mensal de todos os municípios brasileiros em 2017. Todavia, há grande desigualdade entre os estados brasileiros. Em melhor situação estão os municípios dos estados das Regiões Sul e Sudeste (RS = R\$ 776; SP = R $\$ 696$ e SC $=672$, os três primeiros), que são também os menos municipalizados e com maior receita própria. Os valores mais baixos estão concentrados no Norte e Nordeste (MA = R \$325; $\mathrm{AL}=328 ; \mathrm{PA}=\mathrm{R} \$ 356$ ), onde o gasto por aluno com recursos do Fundeb chega a superar $80 \%$ do total. Vale destacar que, dos 11 estados com menores medianas, nove são os que recebem complementação da União via Fundeb, o que evidencia os limites dessa complementação. Em uma análise comparativa entre os estados, verifica-se que a amplitude entre a mediana do gasto por aluno do Rio Grande do Sul e do Maranhão é de 2,4 vezes. Ou seja, a política de financiamento vigente reduziu, mas está longe de eliminar a grande desigualdade entre os estados. Na perspectiva horizontal (intra-estadual), o coeficiente de variação $(\mathrm{CV})$ pode ser tomado como indicador da desigualdade do gasto entre os municípios de cada estado. Vale notar que o Rio Grande do Sul é também o segundo estado mais desigual ${ }^{11}$ ( $\mathrm{CV}=39 \%$ ), somente atrás de Minas Gerais ( $\mathrm{CV}=40 \%$ ). Nesse sentido, vale notar que há forte correlação positiva entre a mediana do gasto por aluno e o $\mathrm{CV}(\mathrm{r}=0,762)^{12}$. Isso significa que, quanto maior a mediana do gasto por aluno em um estado, maior é a desigualdade do gasto entre os municípios desse estado. Ao verificar que entre os menos desiguais estão os estados com a menor mediana do gasto por aluno (AM, AC, PA, PI, MA), é importante recordar a advertência de Moser e Rubenstein (2002) de que não é desejável menor desigualdade se todas as redes escolares investem relativamente pouco em educação. Por isso a importância de uma maior complementação da União.

A Tabela 3 também revela associação negativa entre as medianas do gasto por aluno da rede municipal dos estados e a mediana do resultado líquido do Fundeb $(r=-0,665)$. Isso sugere que a estratégia de alguns municípios de "correr atrás dos recursos do Fundeb", assumindo matrículas estaduais, não se mostrou uma boa estratégia em termos do gasto por aluno da própria rede. Correlação igualmente forte e negativa foi verificada entre a mediana do gasto por aluno da rede municipal dos estados e a mediana da 'razão gasto fundeb / gasto total' ( $r=-0887$ ). Esse resultado sugere que o gasto por aluno é menor nos estados cujos municípios dependem mais dos recursos do Fundeb. Ou seja, possuem menos 'receitas adicionais ao Fundeb' e são mais municipalizados.

10 Lei n 9.394/1996. Art. 74: "A União, em colaboração com os Estados, o Distrito Federal e os Municípios, estabelecerá padrão mínimo de oportunidades educacionais para o ensino fundamental, baseado no cálculo do custo mínimo por aluno, capaz de assegurar ensino de qualidade".

11 Para exemplificar a enorme desigualdade intra-estadual, a amplitude entre o município do Rio Grande do Sul com maior gasto por aluno (Nova Pádua/RS, 2.568 habitantes e 44 matrículas na rede municipal = R $\$ 3.322$ por mês) e o menor (Parobé/RS, 56.277 habitantes, 9.562 matrículas na rede municipal = R $\$ 414$ por mês) é de 8 vezes.

12 Coeficiente de correlação de Pearson $(r)=0,762$, significante ao nível de 0,01. 
Em seguida, foi realizada uma análise de regressão múltipla no intuito de compreender a variação do gasto por aluno (variável de interesse ou dependente) entre os municípios brasileiros, considerando diversas variáveis explicativas (ou independentes) conjuntamente. Esse tipo de análise permite compreender quais variáveis são importantes para determinar o nível de gasto dos municípios e, entre as importantes, qual o nível de impacto de cada uma na determinação do gasto. Antes, porém, foi analisada a correlação entre as variáveis apresentadas no Apêndice $A$ e verificou-se que o gasto por aluno tem correlação positiva forte com a receita por aluno $(r=0,892)$, receita própria $(r=0,817)$ e a RLI por habitante $(r=0,696)$.

Observando os pressupostos da técnica indicados por Hair et al. (2009), foram selecionadas as variáveis explicativas mais correlacionadas ao gasto por aluno e não relacionadas entre si (vide coeficientes de correlação no Apêndice A). Igualmente, foram retirados os valores atípicos. Observando esses aspectos, o modelo de regressão com melhor ajuste utilizou dados de 5.401 municípios e conseguiu explicar $82,5 \%$ da variação do gasto por aluno com quatro variáveis. Os resultados dos testes e análise de resíduos no Apêndice B permitem concluir que o modelo gerou resultados significativos, estatisticamente. O modelo gerou a seguinte equação de regressão:

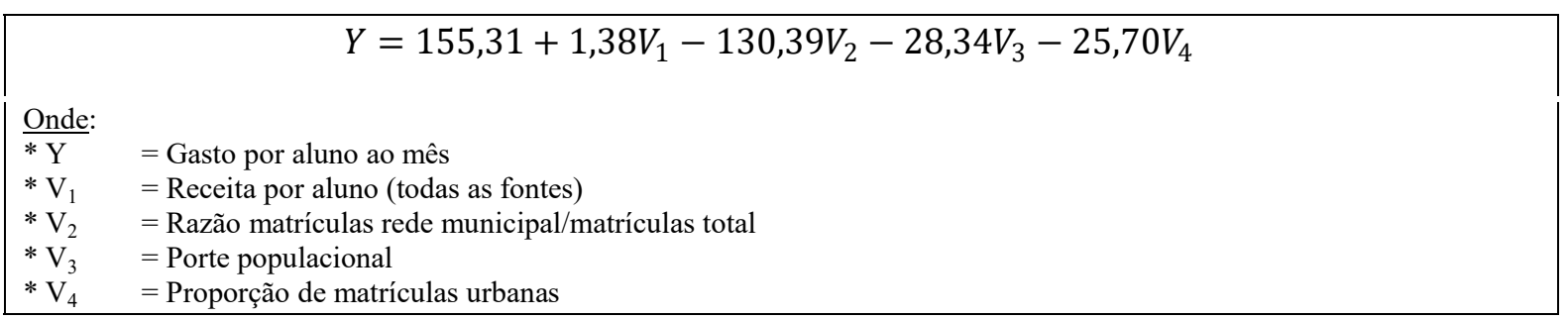

Os valores da equação para o conjunto de dados dos municípios analisados sugerem que: a cada $R \$ 1,00$ de incremento da receita por aluno (por mês), há um aumento de $R \$ 1,38$ no gasto por aluno; a cada $1 \%$ de aumento da participação da matrícula da rede municipal na matrícula total, há uma redução de $\mathrm{R} \$ 130,39$ no gasto por aluno; que, na medida em que aumenta o tamanho populacional em um porte, há uma redução de $R \$ 28,34$ no gasto por aluno; e que, a cada $1 \%$ no aumento de matrículas urbanas, há uma redução de $R \$ 25,70$ no gasto por aluno. Os coeficientes beta padronizados ${ }^{13}$, constantes no Apêndice $B$, indicam que a receita por aluno é a variável que mais impacta o gasto por aluno. Ou seja, o gasto é maior onde o valor-aluno Fundeb é maior e onde, além da receita do Fundeb, há outras fontes de receitas. Ou ainda, porque a rede municipal atende poucos alunos e, por isso, o recurso disponível, ainda que seja pouco, garante altos valores per capita. A receita-aluno-mês tem impacto quatro vezes maior do que a segunda mais relevante (porte populacional). A terceira mais relevante é a proporção da oferta municipal em relação ao total de matrículas da educação básica da localidade e, por fim, a proporção de matrículas urbanas. Esses resultados sugerem, à luz do princípio da neutralidade de riqueza ou neutralidade fiscal (BERNE; STIEFEL, 1984), a necessidade de aumentar a receita da educação por aluno nos municípios por meio da política de financiamento. Isso é fundamental para que a capacidade de financiamento das redes públicas não dependa majoritariamente da capacidade de arrecadação local (decorrente do vigor da economia local) e, assim, que o direito à educação

13 Os coeficientes beta padronizados informam o impacto de cada variável na determinação do valor da variável dependente a um número de desvio-padrão. Desse modo, permite comparar a magnitude do impacto em uma mesma unidade de medida. 
não fique suscetível à capacidade fiscal dos municípios em que os alunos moram. O Fundeb, com mais recursos da complementação da União para ser redistribuído aos municípios com menor receita, como apontam as discussões da PEC 15/2015 no Congresso Nacional, pode ser um instrumento importante para essa equalização. Cabe também lembrar que a análise aqui empreendida se refere apenas às redes municipais. Assim, municípios com elevados gastos por aluno em sua rede, mas com pequena participação total na matrícula local na educação básica, acabam contribuindo pouco para a qualidade da educação ofertada a todos os alunos que ali residem, ficando a maioria sob responsabilidade da rede estadual e em condições de financiamento e qualidade de oferta bem inferiores. Ou seja, falta ainda ao País dar um passo além da política de fundos, criando uma rede pública única em cada UF, de tal forma que não coexistam, em cada município, redes públicas de educação básica com padrões muito distintos. O passo seguinte seria pensar um fundo público único, nacional.

Por fim, a técnica 'análise de agrupamentos' (cluster analysis) foi utilizada para identificar grupos de municípios similares entre si. Observando os objetivos do estudo e os pressupostos da técnica para seleção de variáveis ${ }^{14}, 5.398$ municípios foram classificados em seis grupos similares segundo quatro características: 'gasto por aluno', 'número de escolas', 'proporção da oferta de matrículas pela rede municipal' e 'percentual de receita adicionais ao Fundeb'15. Para análise do perfil dos seis grupos identificados, além das quatro variáveis que definiram os clusters, a Tabela 4 também mostra a mediana dos valores das variáveis 'Resultado Líquido Fundeb' e 'porte populacional'.

Tabela 4 - Características dos agrupamentos de municípios, Brasil, 2017

\begin{tabular}{|c|r|r|r|r|c|c|c|c|}
\hline Grupo & $\begin{array}{c}\text { número de } \\
\text { municípios }\end{array}$ & $\begin{array}{c}\text { total de } \\
\text { matrículas }\end{array}$ & $\begin{array}{c}\text { Gasto-aluno-mês } \\
\text { (R\$) }\end{array}$ & $\begin{array}{c}\text { Número de } \\
\text { escolas da } \\
\text { rede }\end{array}$ & $\begin{array}{c}\text { Part. } \\
\text { Matrículas } \\
\text { municipal }\end{array}$ & $\begin{array}{c}\text { Receitas } \\
\text { adicionais ao } \\
\text { Fundeb }\end{array}$ & RL Fundeb & $\begin{array}{c}\text { Porte } \\
\text { população }\end{array}$ \\
\hline 1 & 887 & 774.163 & 837 & 4 & $48,5 \%$ & $41,6 \%$ & 0,653 & 1 \\
2 & 41 & 1.806 .271 & 637 & 114 & $39,3 \%$ & $49,3 \%$ & 1,585 & 6 \\
3 & 83 & 1.703 .930 & 613 & 65 & $39,8 \%$ & $41,4 \%$ & 1,649 & 6 \\
4 & 2.422 & 5.531 .661 & 578 & 8 & $51,9 \%$ & $31,7 \%$ & 1,165 & 3 \\
5 & 1.832 & 7.323 .654 & 387 & 20 & $71,4 \%$ & $14,0 \%$ & 2,320 & 3 \\
6 & 133 & 2.248 .810 & 352 & 93 & $65,7 \%$ & $11,1 \%$ & 3,332 & 5 \\
\hline Total & $\mathbf{5 . 3 9 8}$ & $\mathbf{1 9 . 3 8 8 . 4 9 5}$ & $\mathbf{5 3 1}$ & $\mathbf{1 0}$ & $\mathbf{5 6 , 1 \%}$ & $\mathbf{2 8 , 5 \%}$ & $\mathbf{1 , 4 1 0 4}$ & $\mathbf{3}$ \\
\hline
\end{tabular}

Notas:

(1) mediana do número de escolas nas redes municipais que compõem o grupo;

(2) mediana da Razão matrículas rede municipal/matrículas total das redes municipais;

(3) mediana das Receitas adicionais ao Fundeb em relação à receita total para educação;

(4) mediana do Resultado Líquido Fundeb - receitas recebidas/ receitas destinadas;

(5) mediana do porte populacional dos municípios.

Fonte: Elaborada pelos autores a partir de dados do Censo Escolar (Inep) 2017 e dados analíticos do Siope (FNDE) 2017.

Os grupos foram numerados em ordem decrescente de acordo com o valor da mediana do gasto-aluno-mês. As cores em tons de verde indicam grupos com gasto por aluno acima da mediana nacional ( $R$ \$ 534); em amarelo, valores próximos à mediana nacional; e, em tons

14 Alguns procedimentos e pressupostos indicados por Hair et al. (2009) para utilização de cluster analysis são: utilização de variáveis métricas; coeficiente de variação >= 15\%; ausência de multicolinearidade (correlação entre variáveis); ausência de valores atípicos.

15 Os agrupamentos foram gerados a partir das seguintes especificações: procedimento hierárquico de agrupamento; medida de distância = euclidiana quadrada; algoritmo aglomerativo = método de ligação completa. As variáveis foram padronizadas com Zscore. Foram retirados os municípios que continham valores atípicos em cada variável (três desvios padrões acima e abaixo da média). 
de vermelho, valores abaixo da referência nacional. As cores possibilitaram a localização espacial dos municípios classificados em cada grupo no território nacional (Mapa 1).

Mapa 1 - Identificação espacial dos agrupamentos de municípios, Brasil, 2017

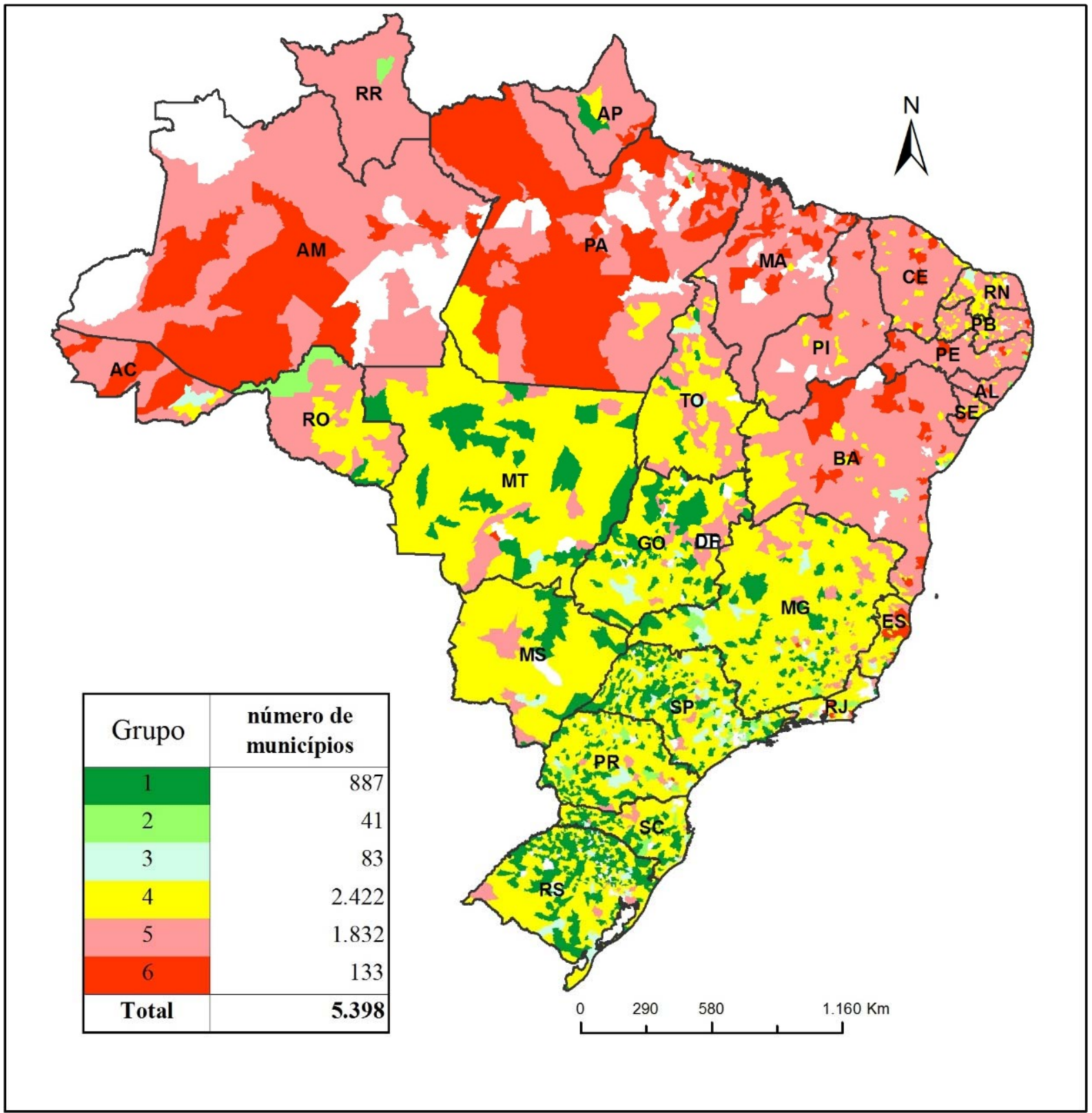

Fonte: Elaborado a partir dos dados do Censo Escolar (Inep) e dados analíticos do Siope (FNDE) 2017 analisados pelos autores. Os autores agradecem a Eunice Cristine Corolo pela espacialização das informações e elaboração do mapa.

O Grupo 1 tem mediana do gasto por aluno igual a R\$ 837 por mês. É composto por 887 municípios majoritariamente de porte 1 (até 5 mil habitantes), com poucas escolas (4), com expressiva proporção de 'receitas adicionais ao Fundeb' $(41,6 \%)$ e redes municipais que ofertam um percentual menor em relação ao total de matrículas da educação básica da localidade (em geral, as redes estaduais ofertam mais e, em menor número de casos, há maior participação da rede privada). Ou seja, esses municípios não necessariamente gastam muito em educação. É que, como atendem menos, o denominador é pequeno e isso resulta em um valor per capita do gasto mais alto. A Tabela 4 mostra que a participação da rede 
As Múltiplas Realidades Educacionais dos Municípios no Contexto do Fundeb

municipal no total das matrículas dos grupos 1, 2 e 3 é consideravelmente menor do que em comparação aos grupos com menor gasto por aluno. Esses municípios, em geral, mais destinam do que recebem recursos do Fundeb em seus estados. Apesar de numeroso, o grupo 1 oferta apenas 774,1 mil, ou $4 \%$ do total de matrículas das redes municipais analisadas. O Mapa 1 mostra que os 887 municípios desse grupo estão majoritariamente em SP, MG, PR, SC e RS. Aparecem também com relativa expressão em GO, MT e MS. 49\% dos municípios do Rio Grande do Sul fazem parte desse grupo.

Os grupos 2 e 3 também têm valores de gasto acima da mediana nacional. Neles estão municípios populosos (porte 6, de 100 mil a 500 mil habitantes). Logo, são os municípios que possuem as maiores redes (em número de escolas) e, por isso, ofertam muitas matrículas (1,8 milhão e 1,7 milhão, respectivamente). Nesses grupos estão nove capitais (Porto Velho/RO, Boa Vista/RR, Belém/PA, Maceió/AL, Aracajú/SE, Vitória/ES, Florianópolis/SC, Rio Branco/AC e Palmas/TO) ${ }^{16}$.

O Grupo 4 tem mediana de gasto por aluno igual a $R \$ 578$ e reúne $45 \%$ dos municípios analisados (2.422). São municípios pequenos (porte 3, com 10 a 20 mil habitantes). Em geral, são responsáveis por metade da oferta de matrículas em suas localidades $(51,9 \%)$, possuem 'receitas adicionais ao Fundeb' $(31,7 \%)$ e recebem recursos do fundeb quase na mesma proporção que destinam (razão 1,165 ). Nesse grupo estão classificados pelo menos $50 \%$ dos municípios de 11 estados brasileiros das Regiões Centro-Oeste (GO, MS e MT), Sudeste (ES, MG, RJ e SP), Sul (PR e SC) e Norte (RO e TO). Essa prevalência (cor amarela) é evidenciada no Mapa 1.

Os grupos 5 e 6 têm medianas do gasto por aluno significativamente menores (a mediana do grupo 5 é 33\% menor do que a mediana do grupo 4, por exemplo). São os grupos assinalados em vermelho no mapa 1. A principal diferença entre os grupos 5 e 6 é o porte populacional e, por consequência, o tamanho da rede em número de escolas. Os municípios do grupo 6 são maiores. Macapá/AP faz parte desse grupo. Em geral, esses municípios assumiram grande parte da oferta de educação básica em suas localidades e possuem menor proporção de 'receitas adicionais ao Fundeb'. Como consequência das duas últimas características, esses municípios recebem mais do que o dobro de recursos que destinam ao Fundeb em seus estados. E, o mais preocupante, esses municípios com recursos tão baixos por aluno atendem quase a metade das matrículas das redes municipais analisadas $(9,6$ milhões ou 49,5\%). Grande parte dos municípios, de 14 dos 16 estados do Norte e Nordeste, estão nesses grupos (100\% no AM; maior ou igual a: $90 \%$ em RR, PA, MA, PI, AL e BA; $80 \%$ no $A C, A P, C E$ e PE; $71 \%$ na PB; $67 \%$ em SE e $64 \%$ no RN).

\section{Considerações finais}

À guisa de considerações finais, destacam-se as evidências do baixo valor e da grande desigualdade do investimento público por aluno nas redes municipais brasileiras. Metade dos municípios apresentam valores de gasto por aluno de até $\mathrm{R} \$ 534$ por mês e um quarto deles contam com apenas R $\$ 266$ por mês. O valor da mediana equivale a menos da metade da

16 Somente 10 das 26 capitais dos estados foram classificadas nos 6 grupos. As demais, por serem municípios de grande porte com características muito específicas nas variáveis consideradas no processo de clusterização, foram excluídas da análise durante os procedimentos de identificação de valores atípicos. 
As Múltiplas Realidades Educacionais dos Municípios no Contexto do Fundeb

mensalidade de uma escola privada frequentada pela classe média e muito menos que o gasto por aluno dos países desenvolvidos.

Os resultados sugerem que apenas municípios com as seguintes características conseguem ter maior nível de gasto por aluno: municípios muito pequenos e com baixo percentual de oferta no território (ou seja, que transferem para a rede estadual a responsabilidade pela oferta). Ou seja, é um valor de gasto por aluno que atinge uma pequena parcela dos alunos, já que a grande maioria está frequentando escolas estaduais com valor por aluno oferecidos pelo Fundeb e que chegam à metade ou menos do gasto por aluno dos poucos "felizardos" da rede municipal. Não são representativos, portanto.

De outro lado, há municípios com um valor de gasto por aluno mais elevado por terem uma receita própria de impostos por habitante elevada e, que, além disso, evitam assumir uma parcela grande da matrícula, o que significa também, como no caso anterior, que no mesmo município há dois padrões de atendimento: aqueles alunos que frequentam uma rede municipal com parâmetros diferenciados de oferta (melhores salários dos profissionais, menor número de alunos por turma, bom nível de equipamentos e infraestrutura); e, de outro, aqueles que frequentam escolas estaduais mantidas basicamente pelos parâmetros do gasto por aluno do Fundeb. São Paulo, a maior cidade do Brasil, seria um exemplo paradigmático desse caso.

Como implicações para as políticas públicas e aperfeiçoamento do Fundeb, ressalta-se:

a) a importância do fortalecimento das instituições que coletam e disseminam dados no nível municipal, como o IBGE e o INEP, com transparência, precisão, regularidade temporal, considerando a importância das informações para subsidiar a formulação, implementação e avaliação de políticas educacionais;

b) a fiscalização da aplicação dos recursos da educação estritamente em MDE nos termos do Art. 70 da LDB como aspecto fundamental para dar precisão ao indicador de gasto por aluno. É primordial o controle e a realização de auditorias frequentes nas folhas de pagamento para que os recursos da educação sejam destinados somente à remuneração dos profissionais da educação. Igualmente, é fundamental que os sistemas de informações avancem no sentido de gerar informações precisas sobre as despesas com cada etapa e modalidade de ensino;

c) a importância de reforçar mecanismos de redistribuição que imprimam maior equidade intraestadual e entre estados no investimento em educação das redes municipais brasileiras;

d) a necessidade de ampliar o complemento federal ao Fundeb para se atingir o CAQi, como determina o PNE. Conforme estudo feito pela Campanha Nacional pelo Direito à Educação (ALVES et al., 2019), uma complementação federal de $40 \%$ no modelo híbrido atingiria cerca de 3 mil municípios brasileiros, exatamente aqueles mais pobres.

\section{Referências}

ALVES, T.; SILVEIRA, A. A. D.; SCHNEIDER, G. Financiamento da Educação Básica: o grande desafio para os municípios. Retratos da Escola, Brasília, v. 13, n. 26, p. 39-413, 2019.

ALVES, T. et al. Novo Fundeb: O sistema híbrido e o direito à educação. Acesso e qualidade. São Paulo: Campanha Nacional pelo Direito à Educação, 2019. (Mimeo). 
As Múltiplas Realidades Educacionais dos Municípios no Contexto do Fundeb

BERNE R.; STIEFEL. L. The measurement of equity in school finance: conceptual, methodological and empirical dimensions. London: The John Hopkins University Press, 1984.

BRAGA, A. S. O poder político do município no Brasil Colônia. Revista Brasileira de Direito Constitucional-RBDC, n. 12, p. 169-232, jul./dez. 2008.

CASTRO, J. A. Financiamento da educação pública no Brasil: evolução dos gastos. In: GOUVEIA, A. B.; PINTO, J. M. R.; CORBUCCI, P. R. (Ed.). Federalismo e políticas educacionais na efetivação à educação no Brasil. Brasília: Ipea, 2011.

FINEDUCA. Associação Nacional de Pesquisa em Financiamento da Educação. Atenção: é preciso proteger o financiamento da educação básica dos prejuízos da crise econômica!. Posicionamentos da Fineduca, São Paulo, 07 maio 2020. Disponível em: <https://fineduca.org.br/2020/05/07/1249>. Acesso em: 25 maio 2020.

GOVERNO propõe extinção de pequenos municípios sem capacidade para se manterem. Folha de São Paulo, São Paulo, 5 nov. 2019. Disponível em: <https://www1.folha. uol.com.br/mercado/2019/11/governo-propoe-extincao-de-municipios-com-baixaarrecadacao.shtml>. Acesso em: 20 maio 2020.

HAIR JR., J.; BLACK, W. C.; BABIN, B. J.; ANDERSON, R. E.; TATHAM, R. L. Análise Multivariada de Dados. 6. ed. Porto Alegre: Bookman, 2009.

IBGE. Instituto Brasileiro de Geografia e Estatística. Evolução da divisão territorial do Brasil: 1872-2010. Rio de Janeiro, 2010. Disponível em: <https://www.ibge.gov.br/ geociencias/organizacao-do-territorio/estrutura-territorial/15771-evolucao-da-divisaoterritorial-do-brasil.html?=\&t=o-que-e>. Acesso em: 16 mar. 2020.

IBGE. Instituto Brasileiro de Geografia e Estatística. Perfil dos Municípios Brasileiros 2018. Rio de Janeiro, 2019.

LEAL, V. N. Coronelismo, enxada e voto. São Paulo: Alfa-ômega, 1978.

MOSER, M.; RUBENSTEIN, R. The in Equality the United of Public States: District Funding Report National Status. Public Administration Review, v. 62, n. 1, p. 63-72, 2002.

PARO, V. H. Participação da comunidade na gestão democrática da escola pública. In: PARO, V. H. Gestão Democrática da Escola Pública. São Paulo: Ed. Ática, 2003.

PINTO, J. M. R. A política recente de fundos para o financiamento da educação e seus efeitos no pacto federativo. Educação \& Sociedade, Campinas, v. 28, n. 100, p. 877-897, out. 2007.

PINTO, J. M. R. Federalismo, descentralização e planejamento da educação: desafios aos municípios. Cadernos de Pesquisa, São Paulo, v. 44, n. 153, p. 624-644, set. 2014a.

PINTO, J. M. R. Dinheiro traz felicidade? A relação entre insumos e qualidade na educação. Education Policy Analysis Archives, Tempe, v. 22, n. 19, 2014b. 


\section{Apêndice A - Análise de correlação ${ }^{1}$ entre as variáveis descritoras dos municípios ${ }^{2}$, Brasil, 2017}

\begin{tabular}{|c|c|c|c|c|c|c|c|c|c|c|c|c|c|}
\hline Variáveis & & V1 & $\mathbf{V} 2$ & $\mathbf{V 3}$ & V4 & V5 & V6 & V7 & V8 & V9 & $\mathbf{V 1 0}$ & V11 & V12 \\
\hline Gasto por aluno (total) & V1 & 1 & & & & & & & & & & & \\
\hline Porte populacional & $\mathrm{V} 2$ &,$- 307^{* *}$ & 1 & & & & & & & & & & \\
\hline Número de escolas municipais & V3 &,$- 343^{* *}$ &, $709^{* *}$ & 1 & & & & & & & & & \\
\hline Razão matrículas rede municipal/matrículas total & V4 &,$- 472 * *$ &,$- 149^{* *}$ & , $091 * *$ & 1 & & & & & & & & \\
\hline Proporção de matrículas urbanas & V5 &, $327^{* *}$ & $-0,02$ &,$- 233 * *$ &,$- 297 * *$ & 1 & & & & & & & \\
\hline Receita Líquida de impostos e transferências por habitante & V6 & $696^{* *}$ &,$- 586 * *$ &,$- 436 * *$ &,$- 059 * *$ &, $339 * *$ & 1 & & & & & & \\
\hline Receita por aluno (todas as fontes) & V7 &, $892 * *$ &,$- 140 * *$ &,$- 231 * *$ &,$- 478 * *$ &, $394 * *$ &, $642 * *$ & 1 & & & & & \\
\hline Participação do Fundeb na receita para educação & V8 &,$- 817^{* *}$ &, $141^{* *}$ &, $279 * *$ &, $599 * *$ &,$- 536 * *$ &,$- 672 * *$ &,$- 846^{* *}$ & 1 & & & & \\
\hline Receita Própria para educação (exceto Fundeb) & V9 &, $817^{* *}$ &,$- 141^{* *}$ &,$- 279^{* *}$ &,$- 599 * *$ &, $536 * *$ &, $672 * *$ &, $846^{* *}$ & $1,000^{* *}$ & 1 & & & \\
\hline Resultado Líquido Fundeb - receitas: recebidas/destinadas & V10 &,$- 660 * *$ &, $489^{* *}$ &, $552 * *$ &, $462 * *$ &,$- 413 * *$ &,$- 671^{* *}$ &,$- 562^{* *}$ &, $743^{* *}$ & * -,743** & 1 & 1 & \\
\hline Gasto por aluno (recursos Fundeb) & V11 &, $597^{* *}$ &,$- 111^{* *}$ &,$- 161^{* *}$ &,$- 190 * *$ &, $120 * *$ &, $316 * *$ &, $694 * *$ &,$- 319 * *$ & *, $319^{* *}$ & *-,183** & 1 & \\
\hline Razão gasto-Fundeb/gasto total & V12 &,$- 861 * *$ &, $289 * *$ &, $387^{* *}$ &, $543 * *$ &,$- 418 * *$ &,$- 653^{* *}$ &,$- 711 * *$ &, $870 * *$ & *,- 870 ** & *, $774 * *$ & $*-, 206^{* *}$ & 1 \\
\hline
\end{tabular}

\section{Notas:}

(1) Foi calculado o coeficiente de correlação de Person para analisar o nível de relação positiva (mesmo sentido) ou negativa (sentido contrário) entre as variáveis. O coeficiente varia de -1 a 1. Valores próximos a zero indicam ausência de correlação; próximos a 0,5 indicam correlação moderada; e acima 0,7 indicam correlação forte;

(2) Foram analisados 5.115 municípios. Foram retirados os municípios que continham valores atípicos em cada variável (três desvios padrões acima e abaixo da média).

Fonte: Elaborada pelos autores a partir de dados do Censo Escolar (Inep) 2017 e dados analíticos do Siope (FNDE) 2017.

\section{Apêndice B}

Model Summary

\begin{tabular}{|l|r|r|r|r|}
\hline Model & R & R Square & \multicolumn{1}{c|}{$\begin{array}{c}\text { Adjusted R } \\
\text { Square }\end{array}$} & $\begin{array}{c}\text { Std. Error of the } \\
\text { Estimate }\end{array}$ \\
\hline 1 &, $908^{\mathrm{a}}$ &, 825 &, 825 & 78,49708 \\
\hline
\end{tabular}

a. Predictors: (Constant), oferta_urbana, porte_pop, oferta_municipal, receita_aluno

b. Dependent Variable: gasto_aluno

ANOVA $^{\mathrm{a}}$

\begin{tabular}{|ll|r|r|r|r|r|}
\hline Model & & Sum of Squares & df & Mean Square & \multicolumn{1}{c|}{ F } & Sig. \\
\hline 1 & Regression & 156455389,398 & 4 & 39113847,349 & 6347,804 &, $000^{\mathrm{b}}$ \\
& Residual & 33249028,719 & 5396 & 6161,792 & & \\
& Total & 189704418,116 & 5400 & & & \\
\hline
\end{tabular}

a. Dependent Variable: gasto_aluno

b. Predictors: (Constant), oferta_urbana, porte_pop, oferta_municipal, receita_aluno 
As Múltiplas Realidades Educacionais dos Municípios no Contexto do Fundeb

\begin{tabular}{|c|c|c|c|c|c|c|c|c|}
\hline \multicolumn{9}{|c|}{ Coefficients $^{\mathrm{a}}$} \\
\hline & & \multicolumn{2}{|c|}{ Unstandardized Coefficients } & $\begin{array}{l}\text { Standardized } \\
\text { Coefficients }\end{array}$ & \multirow[b]{2}{*}{$\mathrm{t}$} & \multirow[b]{2}{*}{ Sig. } & \multicolumn{2}{|c|}{$\begin{array}{c}95,0 \% \text { Confidence Interval } \\
\text { for B } \\
\end{array}$} \\
\hline & & B & Std. Error & Beta & & & $\begin{array}{l}\text { Lower } \\
\text { Bound }\end{array}$ & $\begin{array}{l}\text { Upper } \\
\text { Bound }\end{array}$ \\
\hline 1 & (Constant) & 155,308 & 9,468 & & 16,403 & ,000 & 136,747 & 173,870 \\
\hline & receita_aluno & 1,385 & ,012 & ,806 & 115,590 & 0,000 & 1,361 & 1,408 \\
\hline & oferta_municipal & $-130,394$ & 7,541 &,- 116 & $-17,292$ &, 000 & $-145,177$ & $-115,611$ \\
\hline & porte_pop & $-28,342$ & ,783 &,- 216 & $-36,205$ &, 000 & $-29,876$ & $-26,807$ \\
\hline & oferta_urbana & $-25,704$ & 5,357 &,- 030 & $-4,798$ & 000 & $-36,207$ & $-15,202$ \\
\hline
\end{tabular}
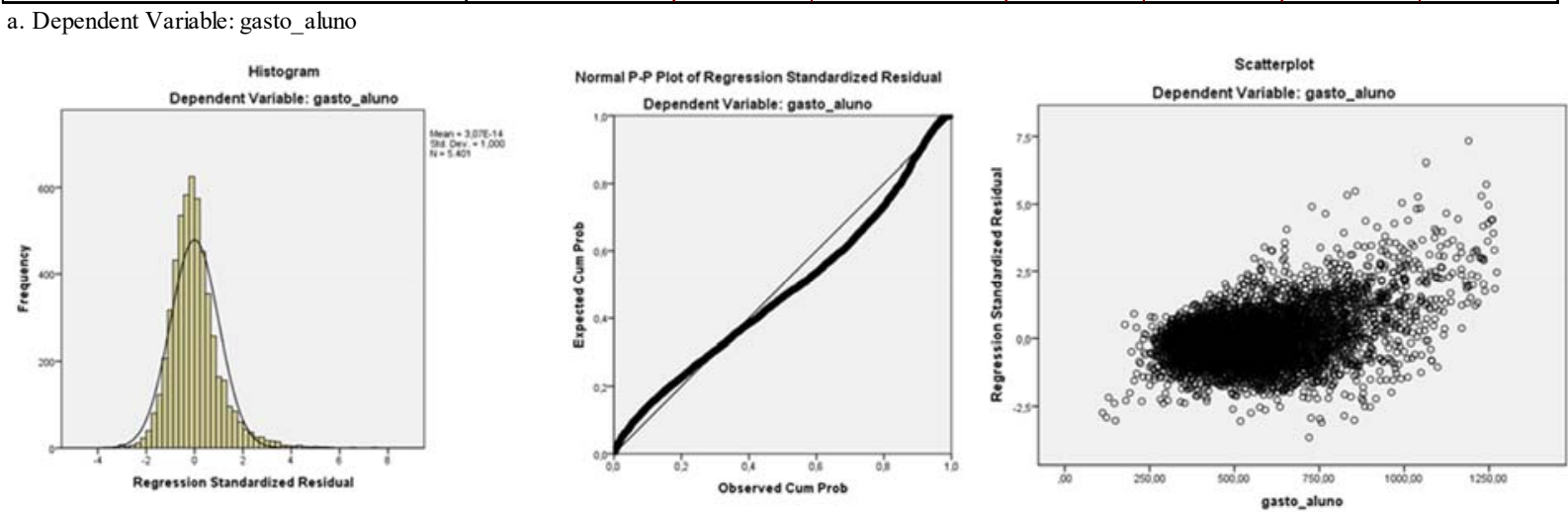

Thiago Alves é doutor em Administração pela Faculdade de Economia, Administração e Contabilidade da Universidade de São Paulo (FEA/USP - 2012), mestre em Administração pela Faculdade de Economia, Administração e Contabilidade de Ribeirão Preto da Universidade de São Paulo (FEA-RP/USP - 2007) e especialista em Finanças e Controladoria pela FEA/USP (2003). Atualmente é professor na Universidade Federal de Goiás.

ORCID: http://orcid.org/0000-0002-5746-3386

E-mail: thiagoalves.edu@gmail.com

José Marcelino de Rezende Pinto é licenciado em Fisica pela Universidade de São Paulo (1982), bacharel em Direito pela Universidade de São Paulo (1985), com mestrado e doutorado em Educação pela Universidade Estadual de Campinas (1989 e 1994). Atualmente é professor titular da Universidade de São Paulo.

ORCID: http://orcid.org/0000-0001-8355-2561

E-mail: jmrpinto@ffclrp.usp.br 


\section{Editores do volume 10}

Márcia Aparecida Jacomini - Universidade Federal de São Paulo, Brasil

José Marcelino de Rezende Pinto - Universidade de São Paulo, Brasil

\section{Comitê Editorial}

Nalú Farenzena - Universidade Federal do Rio Grande do Sul, Brasil

Juca Gil - Universidade Federal do Rio Grande do Sul, Brasil

Theresa Adrião - Universidade Estadual de Campinas, Brasil

Ângelo Ricardo de Souza - Universidade Federal do Paraná, Brasil

\section{Conselho Editorial}

\section{Alejandro Morduchowicz}

Universidad Pedagógica, Provincia de Buenos Aires, Argentina

Andréa Barbosa Gouveia

Universidade Federal do Paraná, Brasil

Fernanda Saforcada

Universidade de Buenos Aires, Argentina

Jacques Velloso

Universidade de Brasília, Brasil

João Monlevade

Senado Federal, Brasil

Jorge Abrahão de Castro

Instituto de Pesquisa Econômica Aplicada / IPEA, Brasil

Lisete Regina Gomes Arelaro

Universidade de São Paulo, Brasil

Luis Carlos Sales

Universidade Federal do Piauí, Brasil

Luiz de Sousa Junior

Universidade Federal da Paraíba, Brasil

Luiz Fernandes Dourado

Universidade Federal de Goiás, Brasil

Magna França

Universidade Federal do Rio Grande do Norte, Brasil

Marcos Edgar Bassi

Universidade Federal de Santa Catarina, Brasil

Maria Angélica Pedra Minhoto

Universidade Federal de São Paulo, Brasil

Maria Beatriz Luce

Universidade Federal do Rio Grande do Sul, Brasil

Maria Dilnéia Espíndola Fernandes

Universidade Federal de Mato Grosso do Sul, Brasil

Nelson Cardoso do Amaral

Universidade Federal de Goiás, Brasil

Nicholas Davies

Universidade Federal Fluminense, Brasil

Robert E. Verhine

Universidade Federal da Bahia, Brasil

Romualdo Portela de Oliveira

Universidade de São Paulo, Brasil

Rosana Gemaque Rolim

Universidade Federal do Pará, Brasil

Rubens Barbosa de Camargo

Universidade de São Paulo, Brasil

Theresa Adrião

Universidade Estadual de Campinas, Brasil

Tristan McCowan

University of London, Reino Unido

Vera Jacob

Universidade Federal do Pará, Brasil

Vera Peroni

Universidade Federal do Rio Grande do Sul, Brasil

Vitor Henrique Paro

Universidade de São Paulo, Brasil

\section{Equipe editorial}

Apoio ao Comitê Editorial: Caio Cabral da Silva

Diagramação, Revisão de português e normalização: Edson Leonel de Oliveira

Revisão de inglês: Sabrina Ferreira

Fineduca - Revista de Financiamento da Educação

Associação Nacional de Pesquisa em

Financiamento da Educação

e-mail: revista.fineduca@gmail.com | site: http://seer.ufrgs.br/fineduca 